\title{
Comparative study of the therapeutic effect of pomegranate alone or in combination with bone marrow mesenchymal stem cells on experimentally induced gastric ulcer in adult male rats: A histological and immunohistochemical study
}

\author{
Original \\ Article \\ Nahla El-Eraky El-Azab ${ }^{1}$, Aisha E. Mansy', Abeer M. El-Mahalaway', Dina Sabry ${ }^{2}$ \\ ${ }^{I}$ Department of Histology and Cell Biology, Benha Faculty of Medicine, Benha University, \\ Egypt \\ ${ }^{2}$ Department of Medical Biochemistry and Molecular Biology, Faculty of Medicine, Cairo \\ University, Cairo, Egypt
}

\begin{abstract}
Introduction: Gastric ulcers are the most prevalent gastrointestinal disorders. Pomegranate fruits have many beneficial therapeutic effects. Bone marrow mesenchymal stem cells (BMSCs) are a novel approach with promising therapeutic potential for curing human diseases.

Aim of the work: To evaluate the effect of pomegranate and BMSCs on experimentally induced gastric ulcer in adult male rats.

Materials and Methods: Sixty adult male rats were divided into four groups. Group I kept as the control group. Group II (Gastric ulcer), rats received 100\% ethanol orally by gastric tube. Group (III) subdivided into 3 subgroups. Subgroup IIIa included rats with gastric ulcer that treated with pomegranate only. Subgroup IIIb, rats with gastric ulcer treated with BMSCs alone. Subgroup IIIc; gastric ulcer rats treated with a combination of pomegranate and BMSCs. Group IV included the untreated gastric ulcer rats. Fundus of stomach specimens were prepared and examined using histological and immunohistochemical techniques.

Results: Groups II and IV showed various changes as deep erosion, marked damage of most of the cells. The presence of the inflammatory cells in gastric mucosa were supported by a significant increase of tumor necrosis factor $\alpha$ (TNF- $\alpha$ ) expression and collagen fibers depositions $(P<0.01)$. A significant decrease of Periodic Acid Schiff (PAS) positive reaction and vascular endothelial growth factor (VEGF) expression was observed $(P<0.01)$. Subgroup IIIa showed attenuation of some histological changes, while subgroups IIIb and IIIc revealed more improvement of the histological and immunohistochemical changes described before.

Conclusion: BMSCs can ameliorate experimentally-induced gastric injury in rats and protect the gastric tissue. Addition of pomegranate to BMSCs can lead to better results.
\end{abstract}

Received: 09 November 2017, Accepted: 12 February 2018

Key Words: Bone marrow mesenchymal stem cells (BMSCs), gastric ulcer, pomegranate, tumor necrosis factor- $\alpha$, vascular endothelial growth factor (VEGF).

Corresponding Author: Nahla El-Eraky El-Azab, Department of Histology and Cell Biology, Faculty of Medicine, Benha University, Benha, Egypt, Tel.: +201027636357, E-mail: eleraky_nahla@yahoo.com

ISSN: 1110-0559, Vol. 41, No.2

\section{INTRODUCTION}

Peptic ulcers are the most prevalent gastrointestinal and global disorders. They include gastric and duodenal ulcer. Gastric ulcer is an interruption of the continuity of the gastric or duodenal mucosa that extends towards the muscularis mucosa and may reach deeper into submucosa ${ }^{[1-3]}$. It can cause major complications such as bleeding, perforation and finally death if associated with decompensating of coexisting medical conditions ${ }^{[1,4]}$.

Gastric ulcers are induced as result of combination of many harmful agents such as stress, smoking, ingesting non-steroidal anti-inflammatory drugs, corticosteroids, food ingredients. Moreover, the disruption of the homeostasis between the defensive (mucin, prostaglandin, bicarbonate, nitric oxide and growth factors) and the offensive factors (increased gastric secretion of pepsin and acid) most commonly by Helicobacter pylori (H. pylori) infection. It affects $10-15 \%$ of the population worldwide and its prevalence rate is associated with age and sex, as well as lifestyle ${ }^{[5,6]}$.

The prevention and therapy of gastric ulcers are a 
medical defy. The approaches to the treatment of gastric ulcers include inhibition of gastric acid secretion by histamine receptor antagonists, antacids, proton pump inhibitors (PPIs), anticholinergic, moreover annihilation of $\mathrm{H}$. pylori. However, all the current therapies are not always effective, have adverse effects, and are expensive with high recurrence rate of ulcer. For this reason, there is a need to search for alternative drug sources or natural products which are more effective and safe against gastric ulcers $^{[3,7]}$. Nowadays, dietary antioxidants of natural products are considered as promising alternative therapy and may have several health benefits ${ }^{[1]}$. The pomegranate (Punica granatum L.) is vastly cultivated in Mediterranean countries as Egypt, Turkey, Tunisia, Spain, and Morocco $^{[8,9]}$. It is consumed fresh, and in other forms "e.g. juice, oil", besides, the extract supplements can also be used $^{[10]}$. Pomegranate is rich in antioxidant of polyphenolic class which includes tannins and anthocyanins and flavonoids ${ }^{[8]}$. Its antioxidant capacity is 3 -fold higher than that of the same amount of green tea or red wine. Moreover, the antioxidant capacity of pomegranate peel extract is 10 times higher than pulp extract ${ }^{[8,10-12]}$. Moreover, pomegranate is a valuable source of many vitamins as $\mathrm{A}, \mathrm{C}$, and $\mathrm{E}$ and folic acid. It also exerts antiatherogenic, anticarcinogenic, anti-inflammatory, antidiarrheal, antimicrobial effects and antidiabetic activities. In addition, the pomegranate has significant role on spermatogenesis and ovulation ${ }^{[8,10,13]}$.

Mesenchymal stem cells (MSCs) provide a promising alternative approach for treating human diseases. They primarily originate from the mesoderm and the ectoderm during early embryonic development and are present in several types of tissues and organs as bone marrow, fat, muscles, lungs, liver, pancreas, and synovial membrane $e^{[2,14,15]}$. MSCs are of great values on clinical proposal because of their easy isolation, multipotency, and high proliferative potential invitro. They can not only work in the hematopoietic system but also migrate into damaged tissues and organs. They are self-renew and can differentiate into their corresponding cells. Moreover MSCs have long-term storage without major loss of potency ${ }^{[15,16]}$.

The present study was conducted to evaluate the effect of pomegranate and bone marrow mesenchymal stem cells (BMSCs) on experimentally induced gastric ulcer in adult male rats.

\section{MATERIALS AND METHODS}

In this study, 60 adult male rats of average weight180-200 g were used. Firm nursing and cleaning procedures were employed to keep the animal in a typical well condition, the animals were settled in animal coop at room temperature $\left(25 \pm 1^{\circ} \mathrm{C}\right)$, relative humidity $(55 \pm 5)$ with $12 \mathrm{~h}$ light $/ 12 \mathrm{~h}$ dark cycle, fed standard basal diet and water ad-libitum, at the animal research laboratory unit, Kasr Al-Ainy Faculty of Medicine, Cairo University.. Rats were acclimated to these conditions for two weeks before beginning the experiment. All morals rules for animal management were monitored. The experimental protocol was advised by the Institutional Animal Care Committee.

\section{Used reagents}

Absolute ethanol were obtained from Merck (Darmstadt, Germany) and Sigma (St. Louis, MO, USA), respectively

\section{Isolation and Labeling of MSCs}

Following strict aseptic procedures; BMSCs prepared and labeled with green fluorescent protein (GFP) (Promega, Madison, WI, USA) in stem cell research unit at the Biochemistry department of the Faculty of Medicine, Cairo University (Cairo, Egypt) according to the method described by Soleimani and Nadri 2009 and Niki et al., $2004^{[17,18]}$. Cultured BMSCs were confirmed by morphology (fibroblast like cells) using an inverted microscope; Leica DM IL LED with camera Leica DFC295 and using fluorescence microscope for tracking of intravenous MSCs (Leica Microsystems CMS GmbH, Ernst-Leitz-Straße 1737, Wetzlar, D-35578, Germany).Fluorescent analysis Cell Sorting (FACS) used for BMSCs which show negativity of CD34+ and positivity of CD105+ specific to MSCs.

\section{Pomegranate peel extracts preparation}

The peels of pomegranate fruits were separated manually and washed with excess water for removal of sugars and adhering material from seeds. The peels were air dried for 48 hours in a ventilated oven at $40^{\circ} \mathrm{C}$ then ground in a grinder to a fine powder and passed through a 24- mesh sieve. Pomegranate peel extract was obtained by alcoholic extraction. Sample of 100 grams fine powdered was extracted with $800 \mathrm{ml}$ ethanol at room temperature for 24 hours in shaking water bath. The mixture filtered through a Whatman No. 2 filter paper for removal of peel particles. The extract were concentrated under reduced pressure in a rotatory evaporator then freeze-dried and stored at $4^{\circ} \mathrm{C}$ in refrigerator while waiting for use $\mathrm{e}^{[19]}$.

\section{Induction of gastric ulcer}

Gastric ulcer was induced by administering intragastric $100 \%$ ethanol $(1 \mathrm{ml} / 200 \mathrm{~g})$ on the second day of starvation using an oral feeding stainless steel 20G, 1.5inch needle. Only one dose of ethanol and after one hour of its administration the gastric ulcer was induced ${ }^{[20]}$.

\section{Experimental design}

Rats were divided into four groups:

Group I (Control groups): Ten rats of this group were further subdivided equally into two subgroups.

Subgroup Ia each rat received $1 \mathrm{ml}$ saline once orally.

Subgroup Ib each rat injected once intravenously with $0.5 \mathrm{ml}$ PBS as a vehicle of stem cells via rat tail vein.

Rats of each subgroup were sacrificed together at same duration with the corresponding experimental groups. 
Group II (Gastric ulcer): This group included 10 rats received $100 \%$ ethanol $(1 \mathrm{ml} / 200 \mathrm{~g})$ orally by gastric tube.

Group III This group included 30 rats that were further subdivided equally into 3 subgroups.

Subgroup IIIa (Gastric ulcer treated with pomegranate): Rats were received extract of pomegranate peel at dose of $400 \mathrm{mg} / \mathrm{kg} /$ day orally with basal diet daily for two weeks following ulcer induction with ethanol as group $\mathrm{II}^{[19]}$.

Subgroup IIIb (Gastric ulcer treated stem cells): Rats were injected intravenously by a single dose of $3 \times 10^{6}$ of labeled MSCs were hanging in $0.5 \mathrm{ml}$ PBS via the rat tail vein, two hours following ulcer induction with ethanol ${ }^{[21,22]}$.

Subgroup IIIc (Gastric ulcer treated with stem cells and pomegranate): Two hours following ulcer induction with ethanol in all rats, a single dose of $3 \times 10^{6}$ of labeled MSCs hanging in $0.5 \mathrm{ml}$ PBS injected intravenously via the rat tail vein. Besides, the extract of pomegranate peel was given at a dose of $400 \mathrm{mg} / \mathrm{kg} /$ day orally with basal diet for two weeks.

Group IV (Untreated gastric ulcer): This group included 10 rats. Gastric ulcer induced by administering $100 \%$ ethanol and rats left without treatment for two week.

Two weeks from the start of experiment, rats from groups IIIa, IIIb, IIIc and IV were sacrificed. While the animals of group II were sacrificed one hour after administration of ethanol.

\section{Evaluation of gastric mucosal lesions (ulcer score)}

The superior portion of the fundus was excised, cut along the greater curvature and softly washed in distilled water. It was overextended on a segment of cork with mucosal surface up for macroscopic examination. The gastric lesions severity was detected with the help of an amplifying glass. The frequency of gastric lesions was also assessed independently by an examiner having no information about the regime of treatment. According to Das and Banerjee (1993) ${ }^{[23]}$, the stage of the ulcer lesion was scored according to the subsequent measure:

0 score $=$ no pathology.

1 score $=$ a small ulcer $(1-2 \mathrm{~mm})$.

2 score $=$ a medium ulcer $(3-4 \mathrm{~mm})$.

4 score $=$ a large ulcer $(5$ to $6 \mathrm{~mm})$.

8 score $=$ a larger ulcer $(>6 \mathrm{~mm})$.

The sum of the severity results in each group of rats divided by the number of animals was expressed as the mean ulcer index (U.I.).

\section{Light microscopic studies}

Stomach specimens (upper portion of the fundus) were fixed in $10 \%$ formalin 48 hours. Paraffin sections (5- $\mu$ m-thick) were prepared, processed and stained with hematoxylin \& eosin (H\&E) to verify histological details, Periodic Acid-Schiff technique (PAS) for mucins and Masson's trichrome for collagen ${ }^{[24]}$. Other sections were placed on positively charged slides for immunohistochemical detection of tumour necrosis factor $\alpha(\mathrm{TNF}-\alpha)$ and vascular endothelial growth factor (VEGF) in the cells of the gastric fundus mucosa.

The specimens of subgroups IIIb and IIIc were divided into two sections. The first section was evaluated for tracing of injected GFP labeled stem cells. The second section were prepared for pervious histological and immunohistochemical staining.

\section{Immunohistochemical studies}

1. Immunohistochemical staining for detection of TNF- $\alpha$ (index for inflammation). The primary monoclonal antibody used was the mouse anti-TNF- $\alpha$ (Santa Cruz Biotechnology, Santa Cruz, California, USA) (1:300 with PBS). The cellular site of the reaction was cytoplasmic brown in color.

2. Immunohistochemical staining for detection of VEGF (index for angiogenesis). The primary monoclonal antibody used was the rabbit anti VEGF (Santa Cruz Company, California, USA)(1:500 with PBS). The cellular site of the reaction was cytoplasmic brown in color.

Immunohistochemical study was conducted using the avidin- biotin peroxidase method, followed by diaminobenzidine (DAB) (Dakopatts, Glostrup, Denmark) was added to slides as a chromogen. Thereafter, the slides were washed with distilled water. Later, the sections were counterstained with hematoxylin. For the negative control the specific primary antibody was substitute by phosphatebuffered saline. A section from human esophagus was used as positive control.

\section{Morphometric analysis}

Ten slides from 10 different specimens of each group were examined and from each slide, ten non-overlapping fields were measured using Leica Qwin 500 image analysis computer system (Leica Microsystems Ltd, Cambridge, UK) at the Pathology department, Faculty of Medicine, Cairo University..

The following measures were assessed: The mean area percentage of PAS positive reaction, collagen fiber content, positive immunoreactivity for TNF- $\alpha$ and VEGF at a magnification of $\times 200$. They were calculated using the color detect menu and in relation to a standard measuring frame.

\section{Statistical analysis}

Data were analyzed using IBM SPSS Statistics software for Windows, Version 20 (IBM Corp., Armonk, 
NY, USA). One-way analysis of variance (ANOVA) with Post Hoc Scheffe's test was applied to compare differences among the groups. In each test, data was evident as the mean $(\mathrm{M})$ value \pm standard deviation $(\mathrm{SD})$ and differences were considered to be significant at $P<0.01$.

\section{RESULTS}

\section{Gastric ulcer index}

In table 1 and figure 1 , the mean UI was significantly increased in groups II and IV compared to group I $(P<0.01)$. There was a significant decrease in subgroups IIIa, IIIb and IIIc compared to group II $(P<0.01)$. Moreover, subgroups IIIb and IIIc revealed significant decreases compared to subgroup IIIa $(P<0.01)$.

\section{Histological study}

Bone marrow derived mesenchymal stem cell characterization

BMSCs were recognized in 7 days culture by inverted microscope as spindle-shaped cells between attached colonies (Figure 2a). FACS analysis for MSCs characterization MSCs showed $0 \%$ positivity for CD34 (Figure 2b) and in (Figure 2c) MSCs showed 99.1\% positivity for CD105. Figure 2D showed labeling of MSCs with GFP (in vitro). GFP labeled MSCs were identified in gastric tissue cryosection using a fluorescent microscope (Figure 2e).

\section{Haematoxylin and eosin staining}

Group I (Control rats): Sections of the control rats showed normal histological architecture of the gastric fundic mucosa composed of epithelium, lamina propria and muscularis mucosa. Lamina propria occupied with tubular gastric glands lying perpendicular to the surface and open into lumen by short narrow pits. The upper most layer of epithelium formed of simple columnar surface mucus cells with basal oval nuclei and foamy cytoplasm. The simple tubular glands were divided into three regions, inner isthmus lined with surface mucous cells, middle neck lined with surface mucous neck cells and parietal cells. The outer basal regions were lined with parietal cells and peptic cells. Parietal cells appeared large with central nuclei and acidophilic cytoplasm, but peptic cells appeared small with basal nuclei and basal basophilic cytoplasm (Figure 3).

Group II (Gastric ulcer): This group showed various histological changes such as deep erosion and marked damage of most of the cells. Nuclear pyknosis and deep acidophilic cytoplasm were seen. There were some exfoliated dead cells appearing in the lumen. The intra epithelial lymphocytes were numerous, inflammatory cells and extravasated RBCs were observed (Figure 4).

Group III: Subgroup IIIa (Gastric ulcer treated with pomegranate): This subgroup showed partial incomplete restoration of epithelium, cellular proliferation and migration to restore epithelial loss. Intra epithelial lymphocytes were seen (Figure 5).

Subgroup IIIb (Gastric ulcer treated with stem cells): This subgroup showed cellular proliferation (proliferation of stem cells in neck region and thus restoration in the neck region), followed by restoration of surface epithelium of gastric mucosa with almost normal mucous cells and gastric pits. Some distorted gastric gland, inflammatory cells and congested blood vessels were seen (Figure 6).

Subgroup IIIc (Gastric ulcer-treated with stem cells and pomegranate): This subgroup showed complete restoration in gastric mucosa, some parietal cells have vacuolated acidophilic cytoplasm and central vesicular nuclei. Part of muscularis mucosa was seen (Figure 7).

Group IV (Untreated gastric ulcer): This group showed erosion of the mucosa with some dead, necrotic debris and area of necrotic mucosa in the lumen. The presence of intra epithelial lymphocytes and inflammatory cells were not prominent (Figure 8).

\section{Periodic acid Schiff reaction}

The control groups revealed intense positive PAS reaction on mucosal surface spread down to the pits, isthmus and neck regions (Figure 9). Group II showed weak PAS positive reaction on mucosal surface, pits and isthmus areas but the reaction was negative in the neck region (Figure 10). Group IIIa showed gastric mucosa with moderate positive PAS reaction on mucosal surface, pits and isthmus parts while it was negative in reaction in the neck region (Figure 11). Group IIIb and group IIIc showed intense positive PAS reactivity on the mucosal surface extending down into the gastric pit, isthmus and neck regions (Figures 12 and 13). Group IV showed weak PAS positive reaction on mucosal surface, pits and isthmus parts, however, it was negative in reaction in the neck region (Figure 14).

\section{Masson's trichrome staining}

The control groups showed few collagen fibers in the thin lamina propria and in between the basal part of fundic glands and in the submucosa (Figure 15). Group II showed dense irregularly arranged collagen fibers between the atrophic fundic glands in the lamina propria as well as in the submucosa at the ulcer base (Figure 16). Subgroup IIIa showed moderate collagen fibers deposition (Figure 17), but collagen fibers deposition was fine in subgroups IIIb and IIIc (Figures 18 and 19). Group IV showed dense irregularly arranged collagen fibers in between the atrophic fundic glands in the lamina propria and submucosa at the ulcer base (Figure 20).

\section{Immunohistochemical stains}

\section{Immunohistochemical staining of TNF- $\alpha$}

Positive TNF- $\alpha$ immunohistochemical staining was demonstrated as brown cytoplasmic reaction (index for inflammation). The control groups showed weak TNF- $\alpha$ 
expression (Figure 21). Group II showed highly positive expression of TNF- $\alpha$ (Figure 22). Moderate expression of TNF- $\alpha$ was found in Subgroup IIIa (Figure 23), but weak in IIIb and IIIc subgroups (Figures 24 and 25). Group IV showed highly positive expression of TNF- $\alpha$ in gastric mucosa (Figure 26).

\section{Immunohistochemical staining of VEGF}

Positive VEGF immunohistochemical staining was demonstrated as brown cytoplasmic reaction (index for angiogenesis) in gastric mucosa. The control groups showed highly positive VEGF expression in gastric mucosa (Figure 27). Group II showed weak expression of VEGF (Figure 28). Subgroup IIIa showed moderate expression of VEGF that appeared first in superficial layer of gastric mucosa (Figure 29). Subgroup IIIb showed highly positive VEGF expression in superficial and basal layers (Figures 30). Also subgroup IIIc had highly positive expression of VEGF in superficial and basal layers of gastric mucosa
(Figures 31). Group IV showed weak expression of VEGF (Figure 32).

\section{Morphometric results}

As shown in tables 3 and 4 and figures 34 and 35: Mean area percentage of Masson's trichrome staining of collagen fibers content and TNF- $\alpha$ immunostaining were significantly increased in groups II and IV compared to group I $(P<0.01)$, but significantly decreased in subgroups IIIa, IIIb and IIIc compared to group II $(P<0.01)$. Subgroups IIIb and IIIc revealed a significant decrease compared to Subgroup IIIa $(P<0.01)$.

As shown in tables 2 and 5 and figures 33 and 36: The mean area percentage of PAS staining of mucin and VEGF immunostaining were significantly decreased in groups II and IV compared with group I $(P<0.01)$, but was significantly increased in Subgroups IIIa and IIIb and IIIc, compared with group II $(P<0.01)$. Subgroups IIIb and IIIc revealed a significant increase compared to Subgroup IIIa $(P<0.01)$.

Table 1: Showing the mean UI and \pm SD in groups I, II, IIIa, IIIb, IIIc and IV with comparison between all groups by Post Hoc Scheffe's test.

\begin{tabular}{lcccccc}
\hline & Group I & Group II & Subgroup IIIa & Subgroup IIIb & Subgroup IIIc & Group IV \\
\hline Mean UI & 0 & 6.4 & 3.2 & 1.1 & 0.6 & 5.6 \\
$\mathrm{SD} \pm$ & 0 & 2.0656 & 1.0328 & 0.5676 & 0.5164 & 2.0656 \\
Significance at $P<0.01$ & $2,3,6$ & $1,3,4,5$ & $1,2,4,5,6$ & $2,3,6$ & $2,3,6$ & $1,3,4,5$ \\
\hline
\end{tabular}

$1==$ Significant and group I

$2==$ Significant and group II

$3==$ Significant and subgroup IIIa

$4==$ Significant and subgroup IIIb

$5=$ Significant and subgroup IIIIc

$6==$ Significant and group IV

Table 2: Showing the mean area $\%$ and \pm SD of PAS-positive mucous cells in groups I, II, IIIa, IIIb, IIIc and IV with comparison between all groups by Post Hoc Scheffe's test.

\begin{tabular}{lcccccc}
\hline & Group I & Group II & Subgroup IIIa & Subgroup IIIb & Subgroup IIIc & Group IV \\
\hline Mean area $\%$ & $7.77 \%$ & $1.93 \%$ & $4.32 \%$ & $5.92 \%$ & $6.86 \%$ & $2.17 \%$ \\
SD & 0.5118 & 0.4108 & 0.4587 & 0.5361 & 0.3411 & 0.3623 \\
Significance at $P<0.01$ & $2,3,4,5,6$ & $1,3,4,5$ & $1,2,4,5,6$ & $1,2,3,5,6$ & $1,2,3,4,6$ & $1,3,4,5$ \\
\hline
\end{tabular}

$1=$ Significant and group I

$2=$ Significant and group II

$3=$ Significant and subgroup IIIa

4= Significant and subgroup IIIb

$5=$ Significant and subgroup IIIc

$6=$ Significant and group IV 
Table 3: Showing the mean area $\%$ and \pm SD of Masson trichrome staining of collagen fiber deposition in groups I, II, IIIa, IIIb, IIIc and IV with comparison between all groups by Post Hoc Scheffe's test.

\begin{tabular}{lcccccc}
\hline & Group I & Group II & Subgroup IIIa & Subgroup IIIb & Subgroup IIIc & Group IV \\
\hline Mean area $\%$ & $0.06 \%$ & $4.07 \%$ & $2.38 \%$ & $0.68 \%$ & $0.28 \%$ & $4.02 \%$ \\
$\mathrm{SD} \pm$ & 0.0410 & 0.6248 & 0.4017 & 0.0804 & 0.0566 & 0.2753 \\
Significance at $P<0.01$ & $2,3,5,6$ & $1,3,4,5$ & $1,2,4,5$ & $2,3,5,6$ & $1,2,3,4,6$ & $1,3,4,5$ \\
\hline
\end{tabular}

$1=$ Significant and group I

$2=$ Significant and group II

$3=$ Significant and subgroup IIIa

$4=$ Significant and subgroup IIIb

$5=$ Significant and subgroup IIIc

$6=$ Significant and group IV

Table 4: Showing the mean area $\%$ and \pm SD of TNF- $\alpha$ immune-expression in groups I, II, IIIa, IIIb, IIIcand IV with comparison between all groups by Post Hoc Scheffe's test.

\begin{tabular}{lcccccc}
\hline & Group I & Group II & Subgroup IIIa & Subgroup IIIb & Subgroup IIIc & Group IV \\
\hline Mean area \% & $0.06 \%$ & $8.08 \%$ & $6.19 \%$ & $6.19 \%$ & $0.14 \%$ & $7.88 \%$ \\
$\mathrm{SD} \pm$ & 0.0262 & 0.6695 & 2.4243 & 2.4243 & 0.0427 & 0.5075 \\
Significance at $P<0.01$ & $2,3,6$ & $1,3,4,5$ & $1,2,4,5$ & $1,2,4,5$ & $2,3,6$ & $1,4,5$ \\
\hline
\end{tabular}

$1=$ Significant and group I

$2=$ Significant and group II

$3=$ Significant and subgroup IIIa

4= Significant and subgroup IIIb

$5=$ Significant and subgroup IIIc

$6=$ Significant and group IV

Table 5: Showing the mean area $\%$ and \pm SD of VEGF immuno-expression in groups I, II, IIIa, IIIb, IIIc and IV with comparison between all groups by Post Hoc Scheffe's test.

\begin{tabular}{|c|c|c|c|c|c|c|}
\hline & Group I & Group II & Subgroup IIIa & Subgroup IIIb & Subgroup IIIc & Group IV \\
\hline Mean area $\%$ & $4.13 \%$ & $1.20 \%$ & $1.74 \%$ & $3.55 \%$ & $4.41 \%$ & $1.29 \%$ \\
\hline $\mathrm{SD} \pm$ & 0.2909 & 0.2743 & 0.8075 & 0.3967 & 0.4145 & 0.3605 \\
\hline Significance at $P<0.01$ & $2,3,6$ & $1,3,4,5$ & $1,2,4,5$ & $2,3,5,6$ & $2,3,4,6$ & $1,4,5$ \\
\hline
\end{tabular}

$1=$ Significant and group I

$2=$ Significant and group II

$3=$ Significant \& subgroup IIIa

4= Significant and subgroup IIIb

5= Significant and subgroup IIIc

$6=$ Significant and group IV 


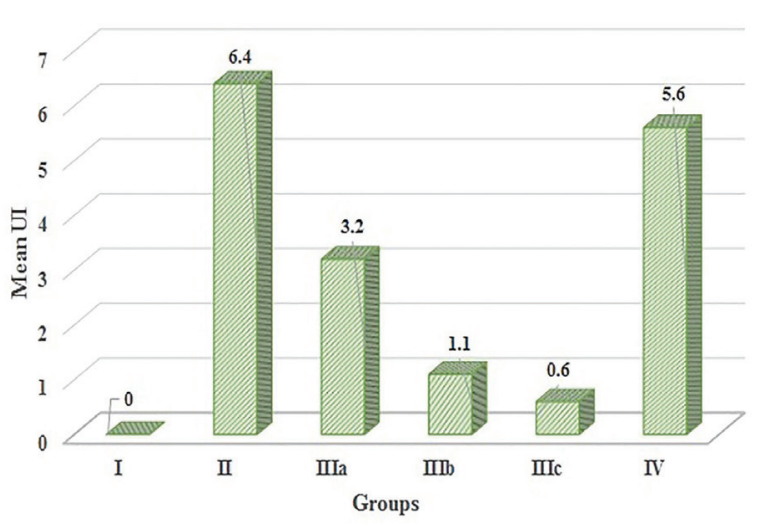

Fig. 1: Showing the mean UI in all experimental groups.
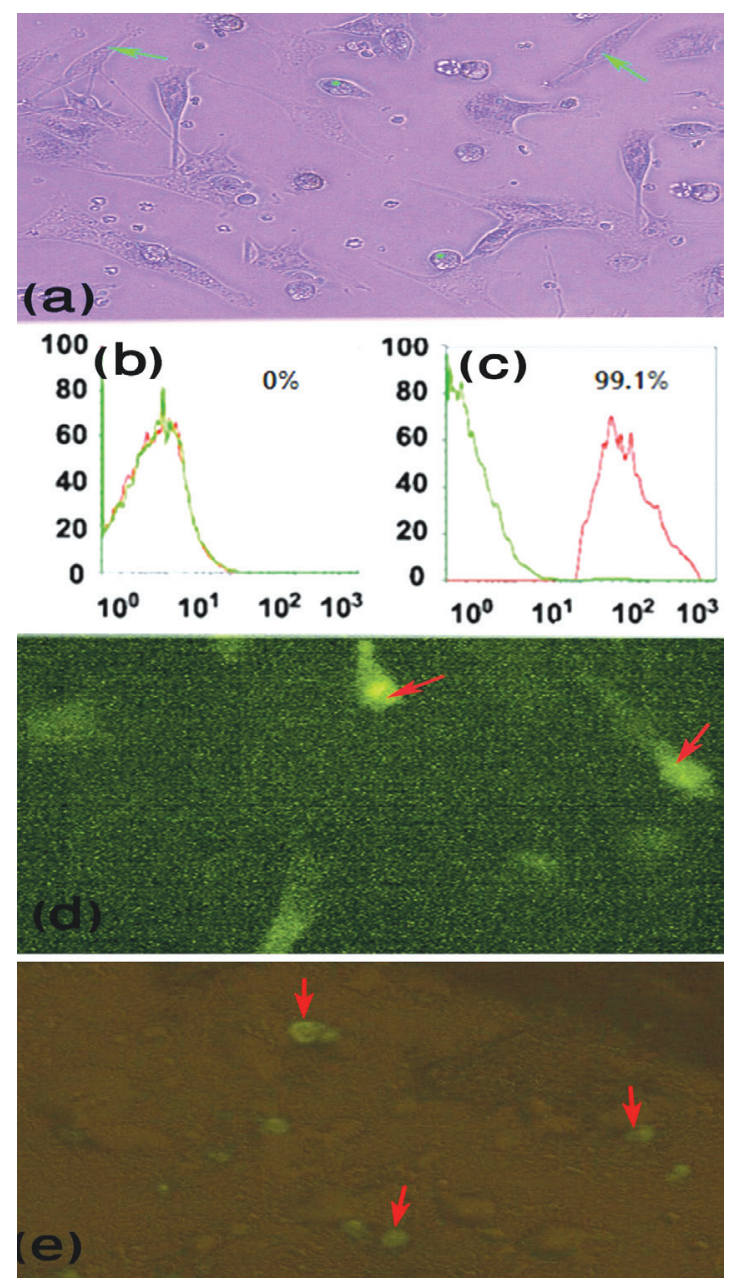

Fig. 2: (a). An inverted microscope micrograph of a primary culture of BMSCs on day 7 showing attached cells form colonies (*) and spindle shaped stem cells $(\uparrow) ., \times 200$. FACS analysis for MSCs characterization in Figure 2 (b). MSCs showing $0 \%$ positivity for CD34 and in Figure 2 (c). MSCs showing $99.1 \%$ positivity for CD105. Figure 2 (d). A fluorescent microscope photograph showing MSCs labeled with GFP in vitro (arrows)., $\times 200$. Figure 2 (e). A fluorescent microscope photograph of gastric mucosa cryosection showing MSCs labeled with GFP in gastric tissue (arrows)., $\times 200$.

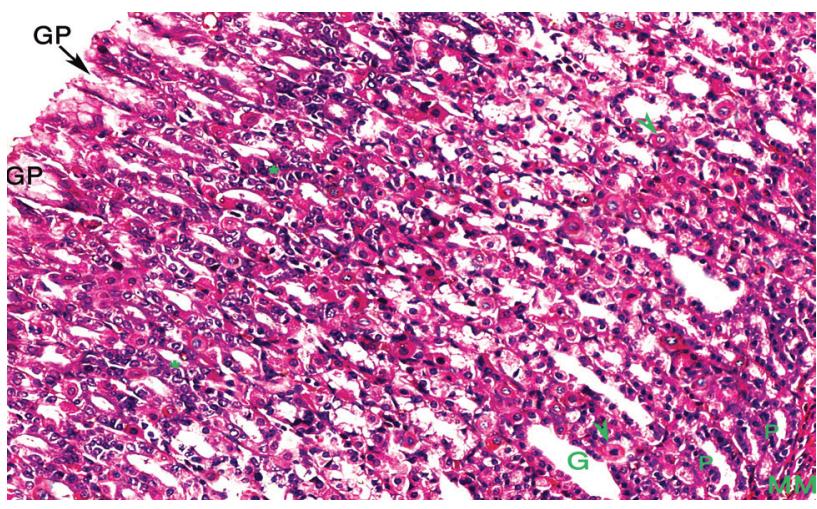

Fig. 3: A photomicrograph of fundic mucosa of group I showing the normal architecture of the gastric mucosa with normal epithelial lining. The lamina propria is occupied with the fundic glands and is separated from the submucosa by muscularis mucosa (MM). The gastric pits (GP) are seen. The fundic glands $(\mathrm{G})$ are lined by mucous neck cells $(*)$, large polyhedral parietal cells ( $\boldsymbol{\Delta}$ arrow heads) while their bases are lined mainly with peptic cells (P) (H\&E x200).

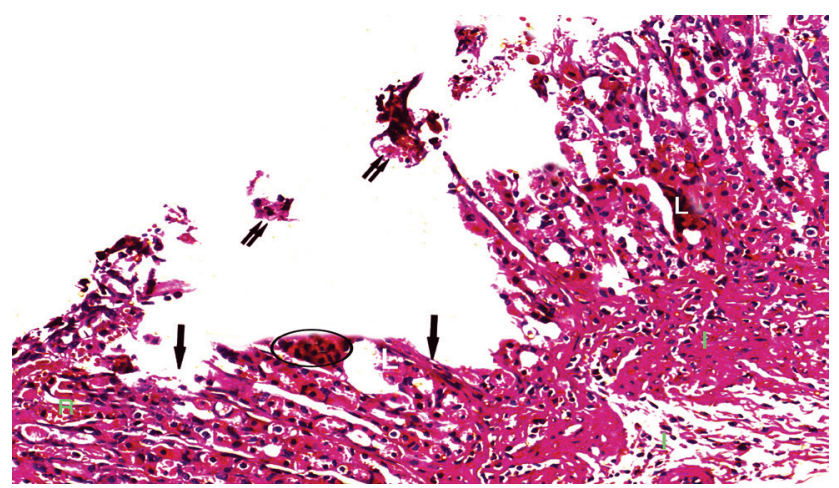

Fig. 4: A photomicrograph of fundic mucosa of group II showing deep erosion near to muscularis mucosa. Marked damage of most of the cells (arrow), nuclear pyknosis with deep acidophilic cytoplasm (circle) are seen. Exfoliated dead cells appear in the lumen (double arrow). Notice the presence of intra epithelial lymphocytes (L) and extravasated RBCs (R) (H\&E x 200).

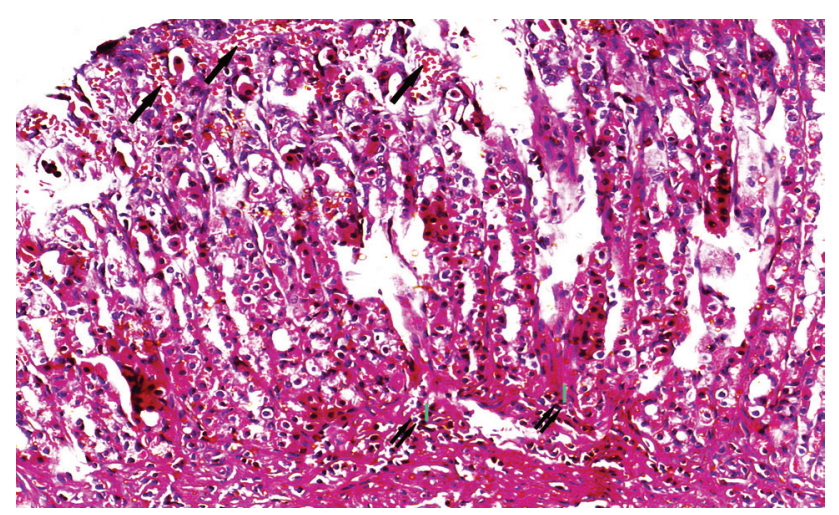

Fig. 5: A photomicrograph of fundic mucosa of subgroup IIIa showing partial incomplete restoration of epithelium. Notice the extravasation of blood (arrow), inflammatory cell as intraepithelial lymphocyte infiltrate (two arrows I) and cellular proliferation to restore the damaged cells (H\&E x200). 


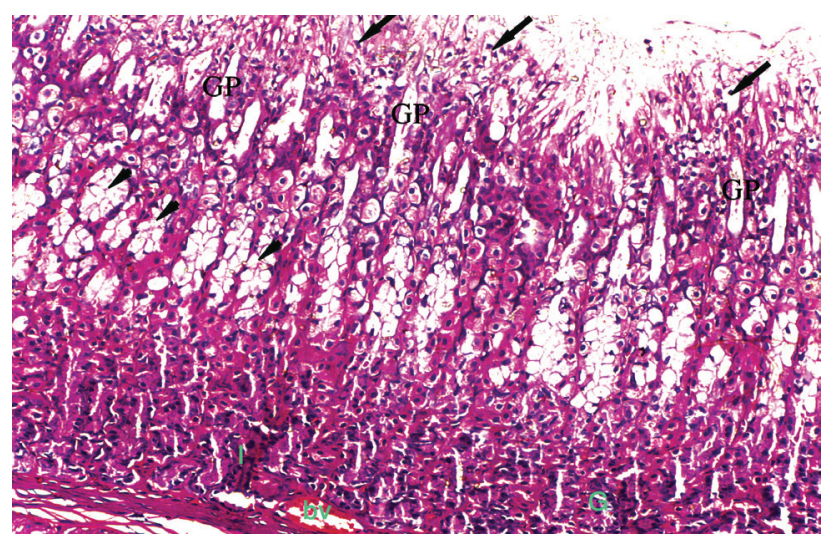

Fig. 6: A photomicrograph of fundic mucosa of subgroup IIIb showing complete restoration by proliferation of stem cell in neck region of gastric mucosa with almost normal mucous cells (arrow head) and gastric pits (GP). Some distorted gastric gland (G), inflammatory cell infiltrate (I) and congested blood vessels (bv) are seen $(H \& E \times 200)$.

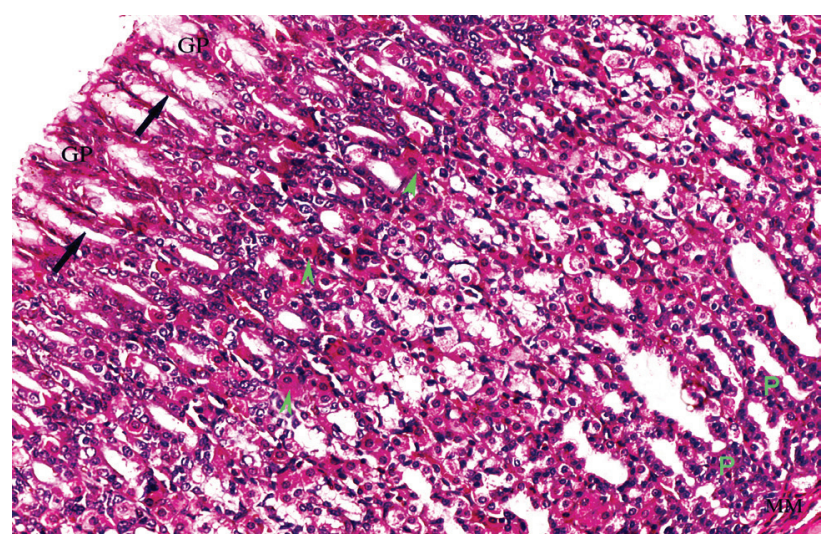

Fig. 7: A photomicrograph of fundic mucosa of subgroup IIIc showing complete restoration in gastric mucosa with normal mucous cells (arrow) and large parietal cells $(\boldsymbol{\Delta}$ arrow heads). Some parietal cells showed vacuolation (P) (H\&E x200).

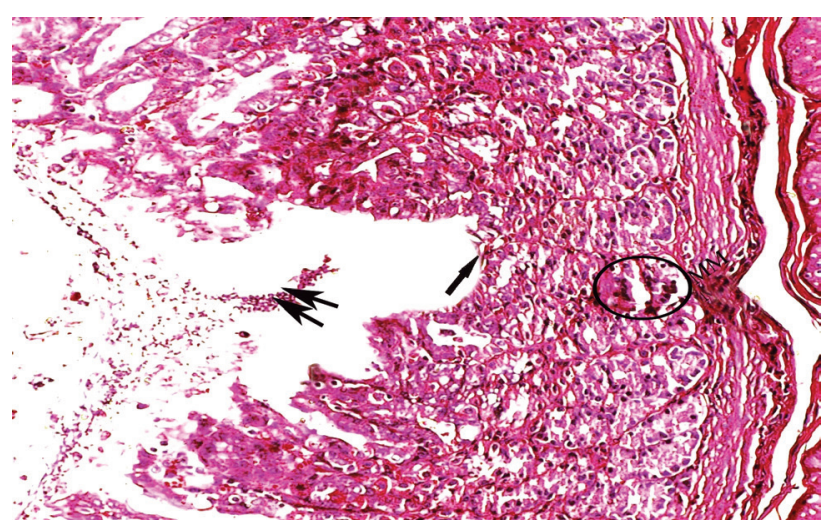

Fig. 8: A photomicrograph of fundic mucosa of group IV showing erosion of the mucosa (arrow), necrotic debris (two arrows) are seen in the lumen. Notice the presence of area of necrosis with acidophilic cytoplasm and deep stained nuclei (circle), but intra epithelial lymphocytes are not prominent (H\&E x 200).

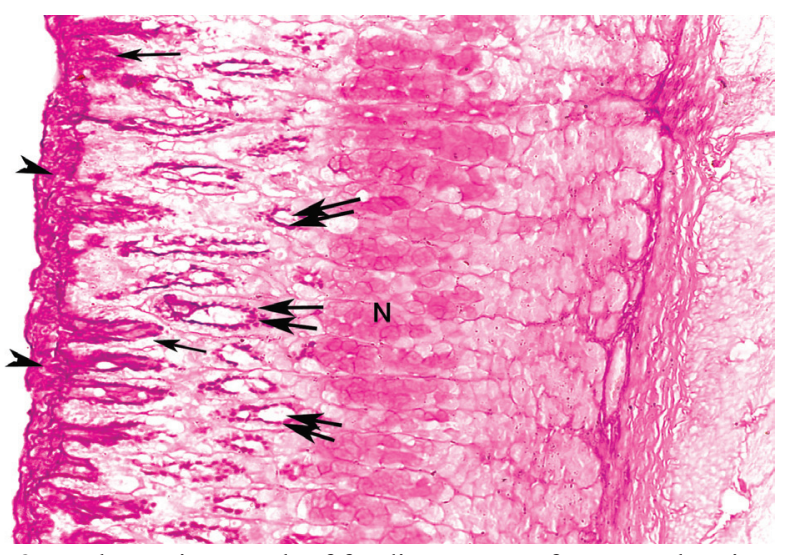

Fig. 9: A photomicrograph of fundic mucosa of group I showing intense PAS positive reaction in mucosal surface ( $\boldsymbol{\Delta}$ arrow heads) spread down to pits (arrow), isthmus (two arrows) and neck regions $(\mathrm{N})(\mathrm{PAS} \times \mathrm{200})$.

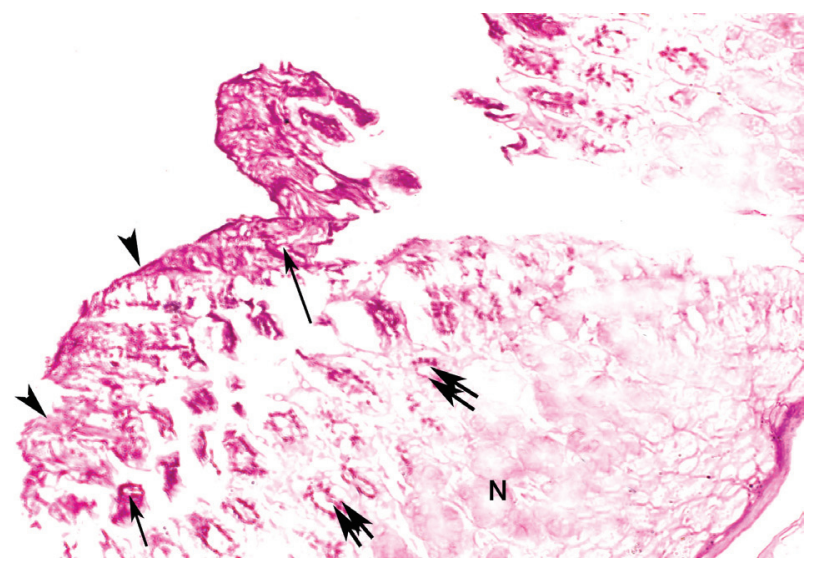

Fig. 10: A photomicrograph of fundic mucosa of group II showing weak PAS positive reaction on mucosal surface ( $\boldsymbol{\Delta}$ arrow heads), pits (arrow) and isthmus areas (two arrows). Notice negative reaction in neck region $(\mathrm{N})(\mathrm{PAS} \times 200)$.

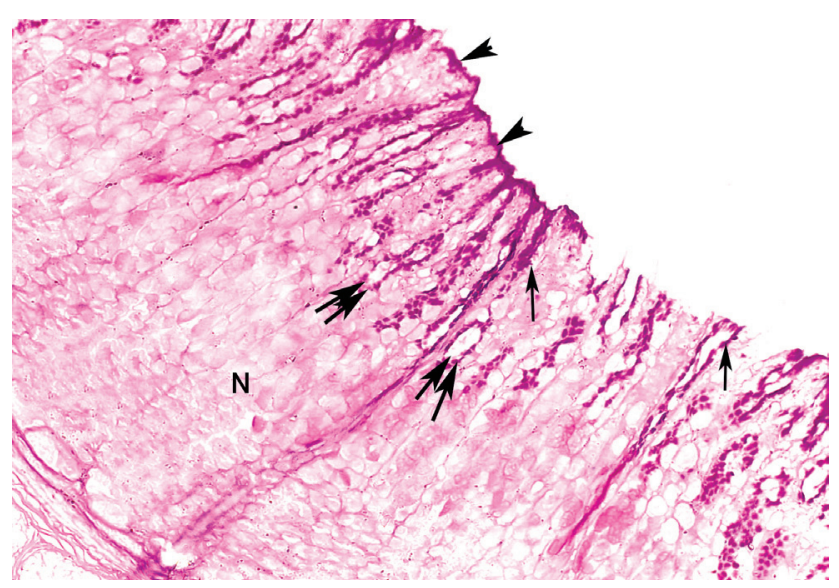

Fig. 11: A photomicrograph of fundic mucosa of subgroup IIIa showing moderate PAS positive reaction on mucosal surface ( $\boldsymbol{\Lambda}$ arrow heads), pits (arrow), isthmus parts (two arrows). Negative reaction in neck region is seen (N) (PAS x 200). 


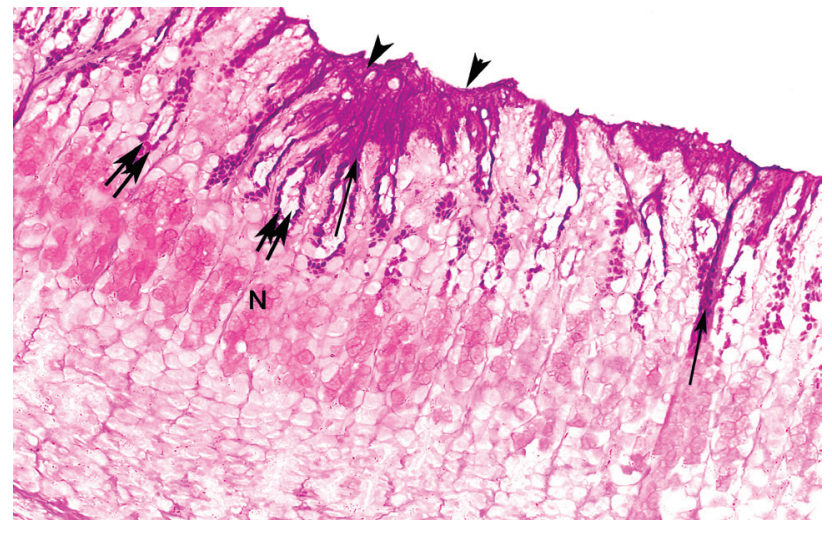

Fig. 12: A photomicrograph of fundic mucosa of a male rat from subgroup IIIb showing intense PAS positive reaction on mucosal surface ( $\boldsymbol{\Lambda}$ arrow heads) outspreading to pits (arrow), isthmus (two arrows) and neck regions (N) (PAS x 200).

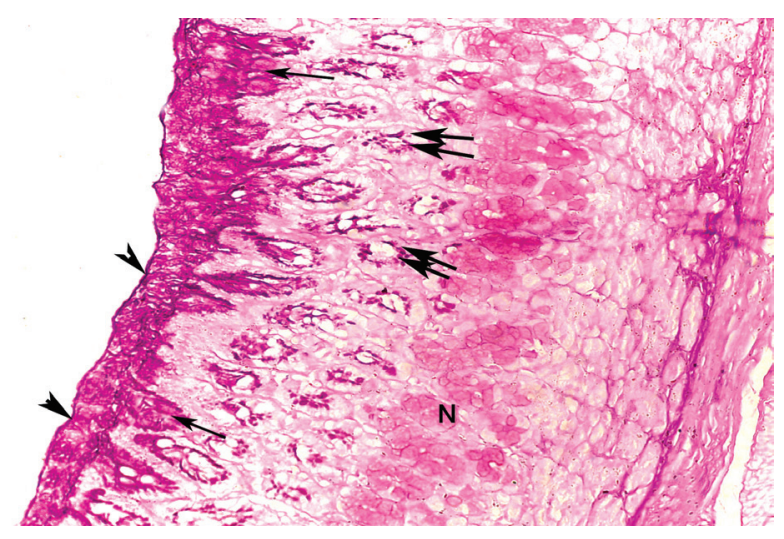

Fig. 13: A photomicrograph of fundic mucosa of subgroup IIIc showing intense PAS positive reaction on mucosal surface ( $\boldsymbol{\Delta}$ arrow heads) spreading down to pits (arrow), isthmus cells (two arrows) and neck regions (N) (PAS x 200).

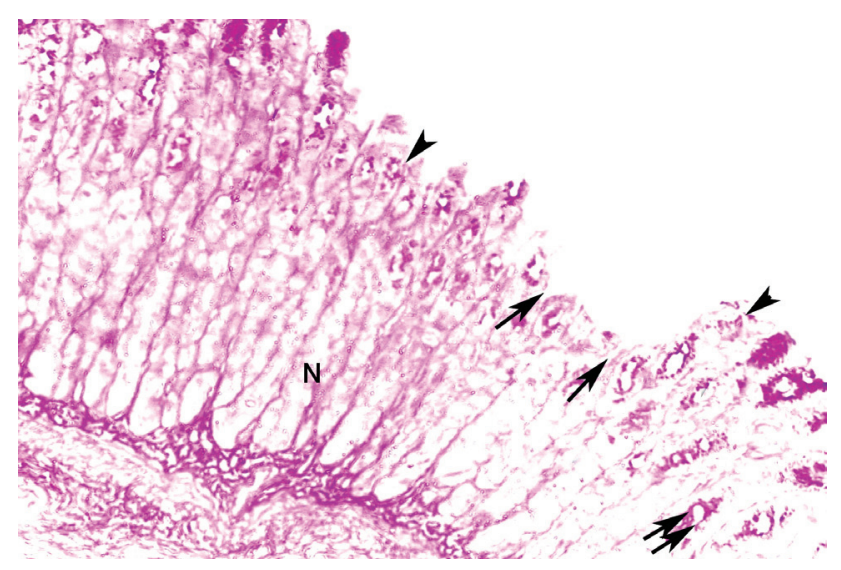

Fig. 14: A photomicrograph of fundic mucosa of from group IV showing positive PAS reaction in surface mucus cells ( $\boldsymbol{\Delta}$ arrow heads), pits (arrow) and isthmus cells (double arrow). Notice negative reaction in neck region (N) (PAS x 200).

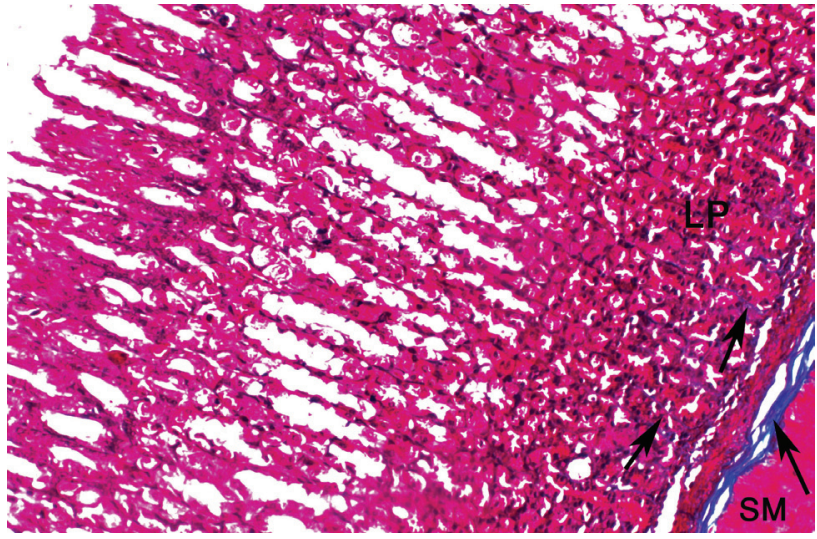

Fig. 15: A photomicrograph of fundic mucosa of group I showing fine collagen fibers between glands (arrow) in the lamina propria (LP) and submucosa (SM) (Masson's Trichrome x 200).

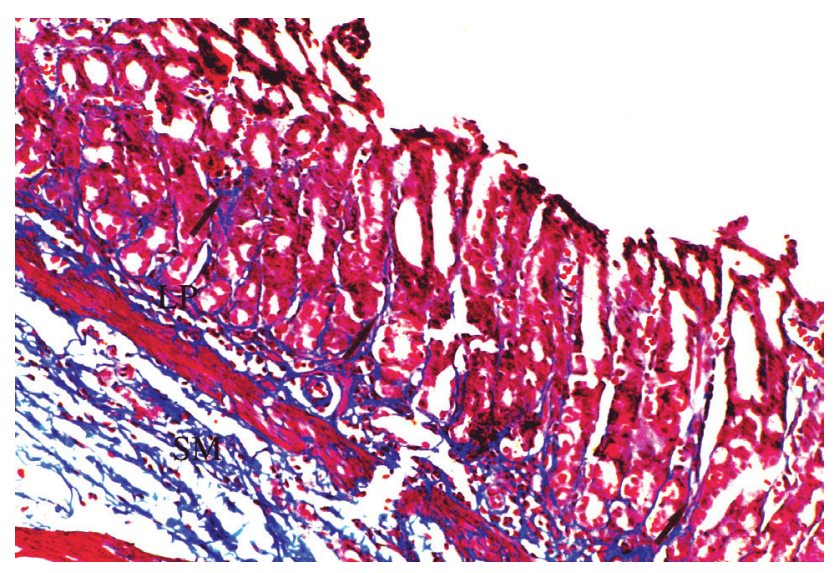

Fig. 16: A photomicrograph of fundic mucosa of group II showing dense irregularly arranged collagen fibers between glands (arrow) in the lamina propria (LP) and submucosa (SM) (Masson's Trichrome x 200).

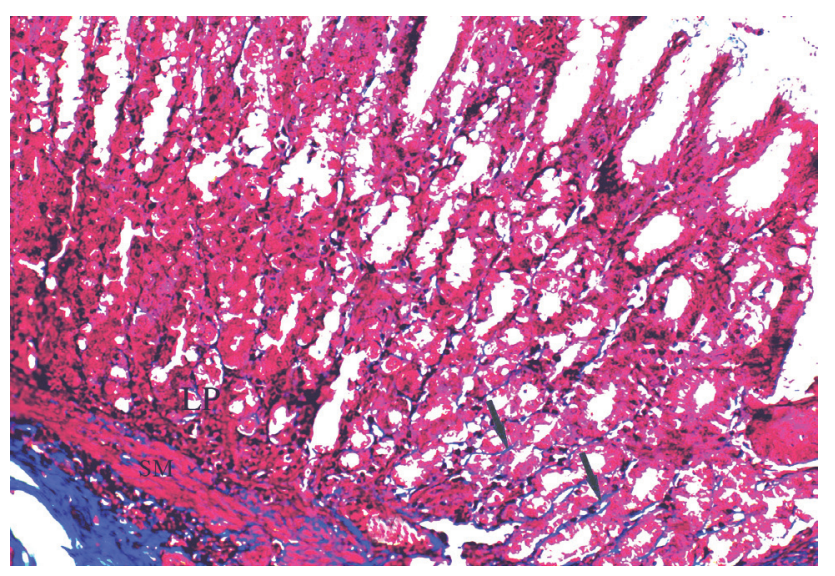

Fig. 17: A photomicrograph of fundic mucosa of subgroup IIIa showing moderate collagen fibers deposition between glands (arrow) in the lamina propria (LP) and submucosa (SM) (Masson's Trichrome x 200). 


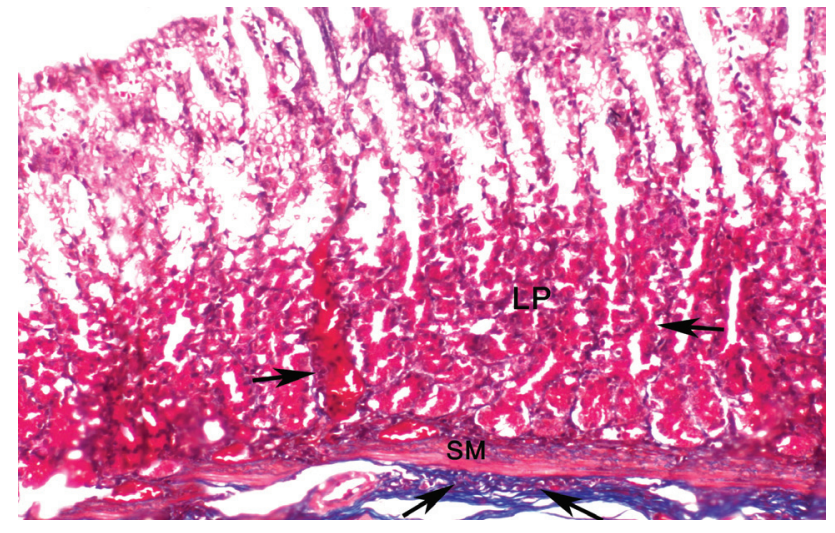

Fig. 18: Showing fine collagen fibers deposition between glands (arrow) in the lamina propria (LP) and submucosa (SM). A photomicrograph of fundic mucosa of subgroup IIIb (Masson's Trichrome x 200).

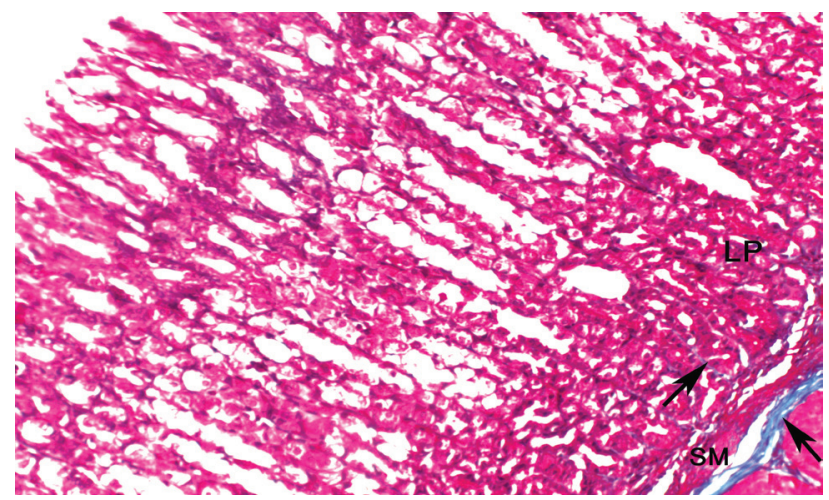

Fig. 19: A photomicrograph of fundic mucosa of subgroup IIIc showing fine collagen fibers deposition between glands (arrow) in the lamina propria (LP) and submucosa (SM) (Masson's Trichrome x 200).

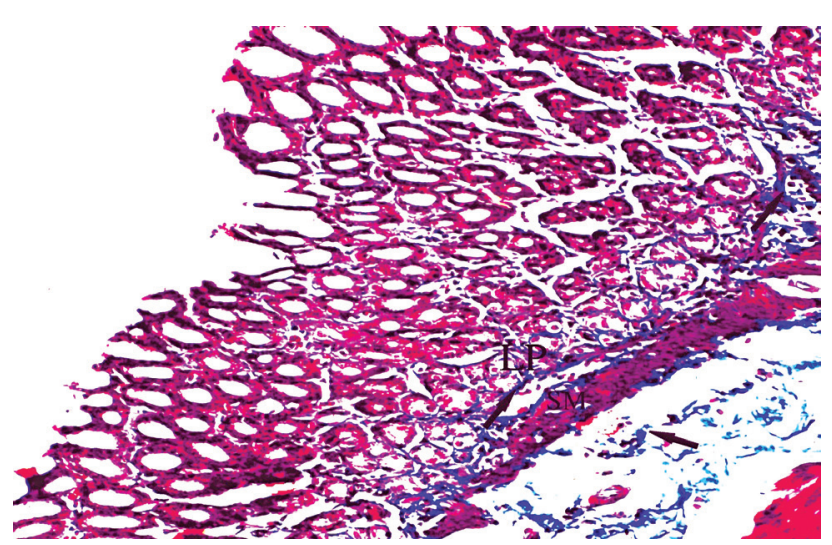

Fig. 20: A photomicrograph of fundic mucosa of group IV Showing dense irregularly arranged collagen fibers between glands (arrow) in the lamina propria (LP) and submucosa (SM) (Masson's Trichrome x 200).

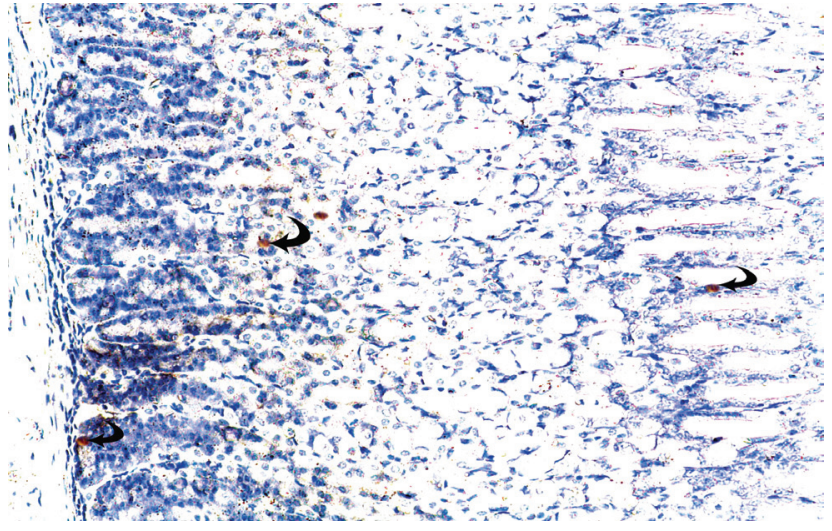

Fig. 21: A photomicrograph of fundic mucosa of group I showing weak positive TNF- $\alpha$ immunoreaction (curved arrow) in gastric mucosa (Immunostaining for TNF- $\alpha \times 200$ ).

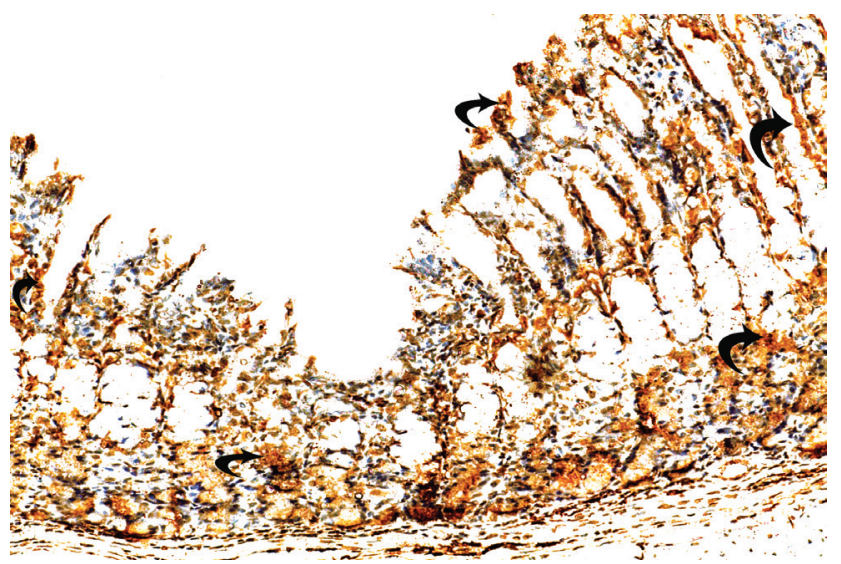

Fig. 22: A photomicrograph of fundic mucosa of group II showing highly positive TNF- $\alpha$ immunoreaction (curved arrow) in gastric mucosa (Immunostaining for TNF- $\alpha \times 200$ ).

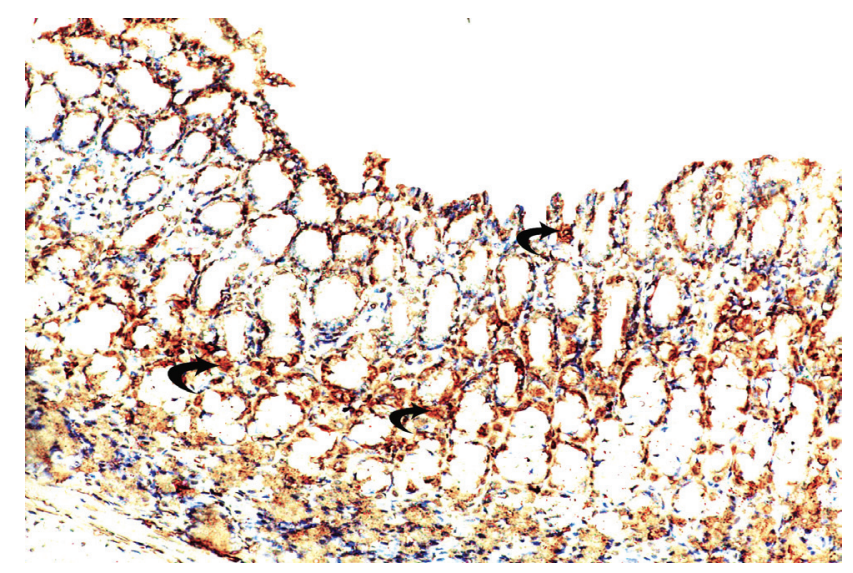

Fig. 23: A photomicrograph of fundic mucosa of subgroup IIIa showing moderate TNF- $\alpha$ immunoreaction (curved arrow) in gastric mucosa (Immunostaining for TNF- $\alpha \times 200$ ). 


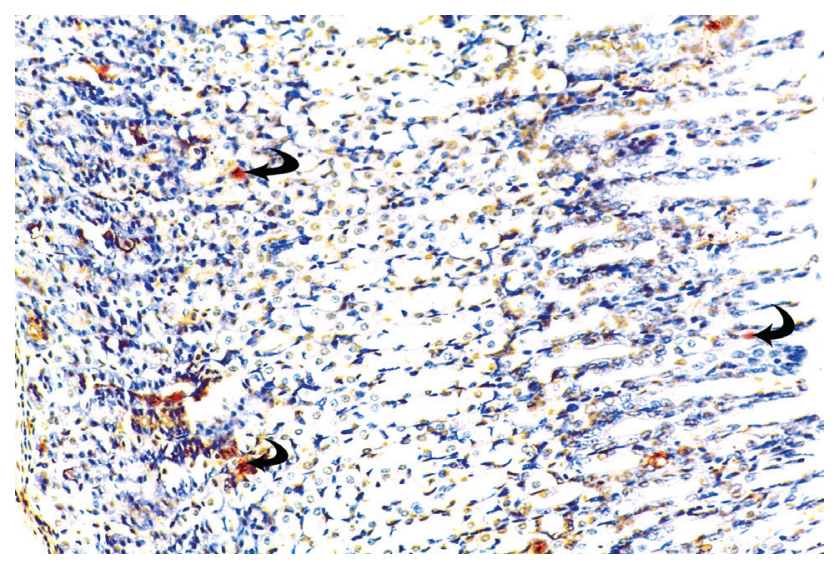

Fig. 24: A photomicrograph of fundic mucosa of subgroup IIIb showing weak TNF- $\alpha$ immunoreaction(curved arrow) in gastric mucosa (Immunostaining for TNF- $\alpha \times 200$ ).

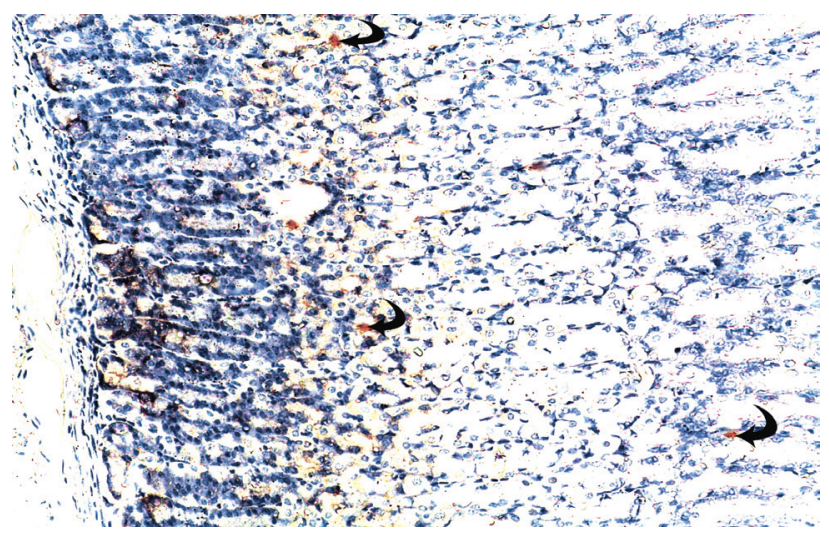

Fig. 25: A photomicrograph of fundic mucosa of subgroup IIIc showing weak TNF- $\alpha$ immunoreaction (curved arrow) in gastric mucosa (Immunostaining for TNF- $\alpha \times 200$ ).

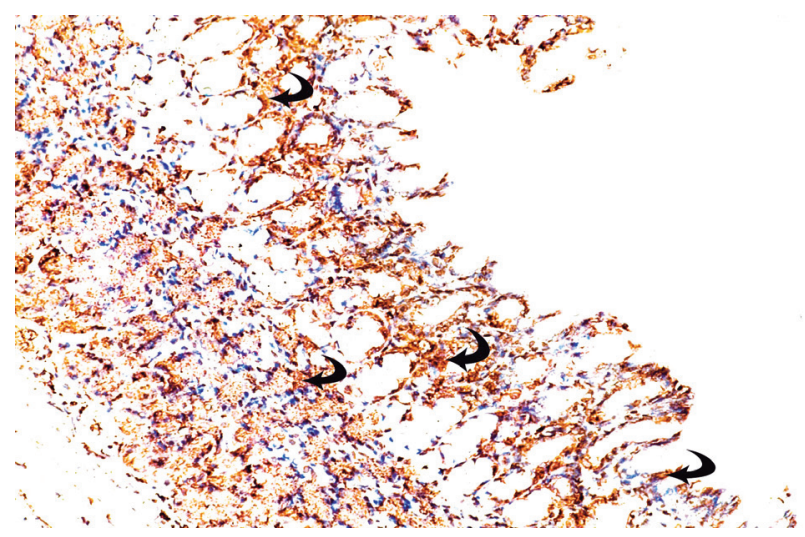

Fig. 26: A photomicrograph of fundic mucosa of group IV showing highly positive TNF- $\alpha$ immunoreaction (curved arrow) in gastric mucosa (Immunostaining for TNF- $\alpha \times 200$ ).

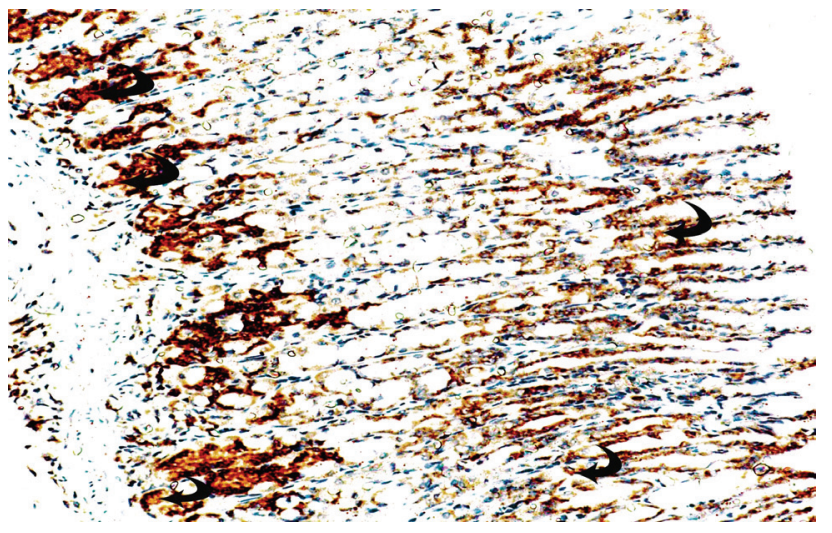

Fig. 27: A photomicrograph of fundic mucosa of group I showing highly positive VEGF immunoreaction (curved arrow) in gastric mucosa (Immunostaining for VEGF $\times 200$ ).

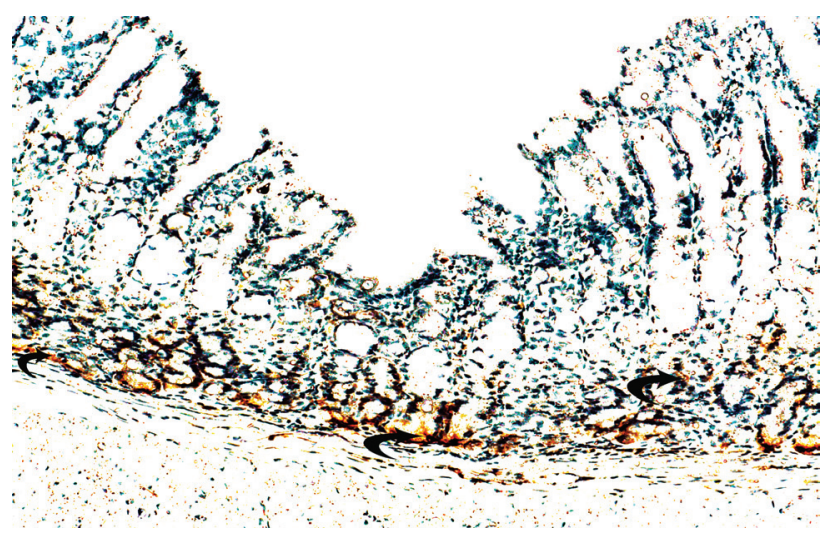

Fig. 28: A photomicrograph of fundic mucosa of group II showing weak VEGF immunoreaction (curved arrow) in gastric mucosa (Immunostaining for VEGF $\times 200$ ).

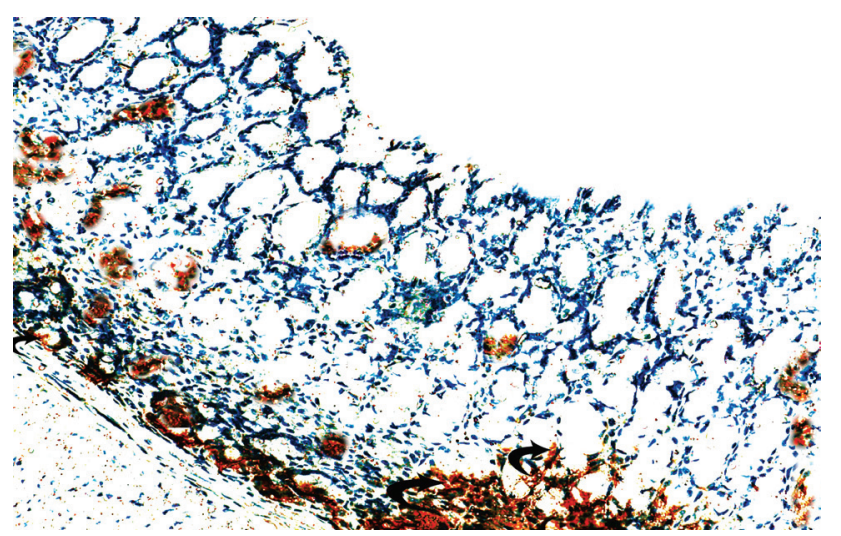

Fig. 29: A photomicrograph of fundic mucosa of subgroup IIIa showing moderate VEGF immunoreaction (curved arrow) in gastric mucosa, which start to appear in superficial layer (Immunostaining for VEGF $\times 200$ ). 


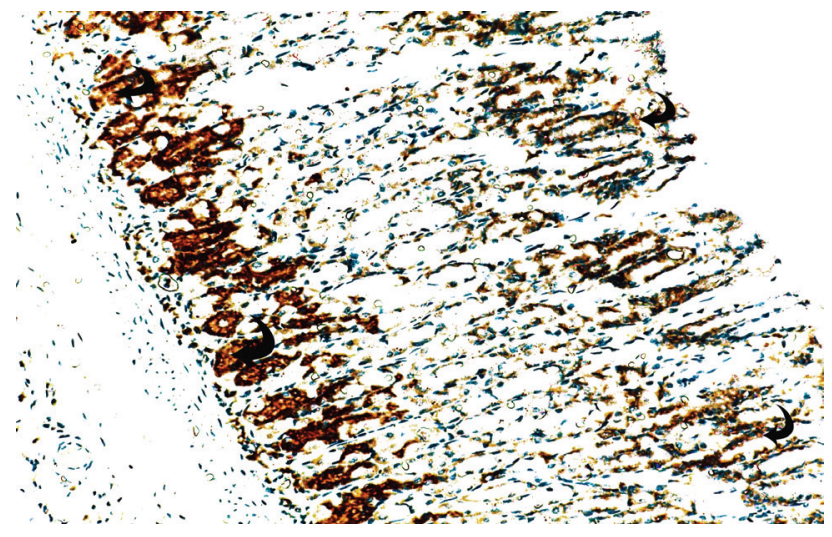

Fig. 30: A photomicrograph of fundic mucosa of subgroup IIIb showing highly positive VEGF immunoreaction (curved arrow) in basal and superficial and basal layers of gastric mucosa (Immunostaining for VEGF $\times 200$ ).

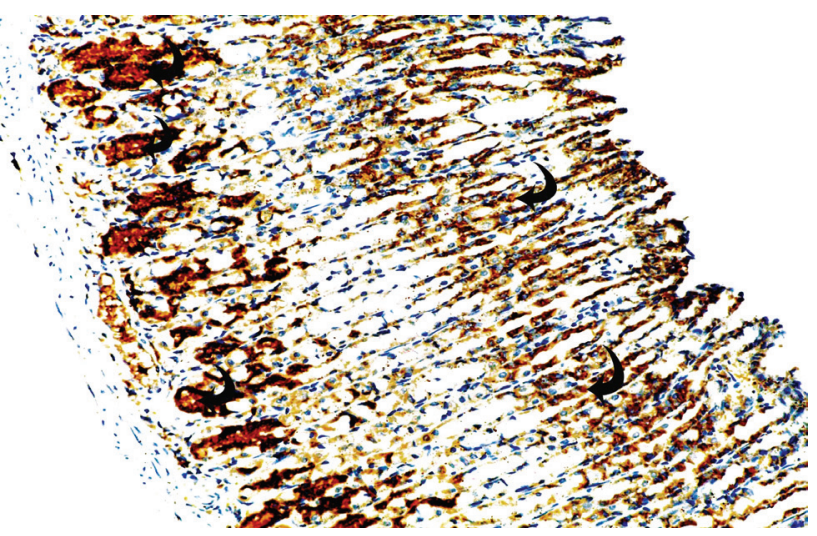

Fig. 31: A photomicrograph of fundic mucosa of subgroup IIIc showing highly positive VEGF immunoreaction (curved arrow) in superficial and basal layers of gastric mucosa (Immunostaining for VEGF $\times 200)$.

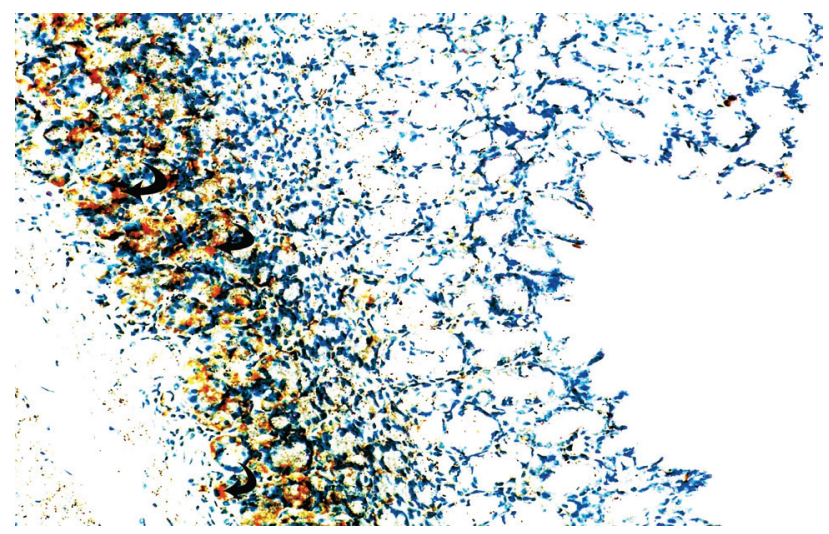

Fig. 32: A photomicrograph of fundic mucosa of group IV showing weak VEGF immunoreaction (curved arrow) in gastric mucosa (Immunostaining for VEGF $\times 200$ ).

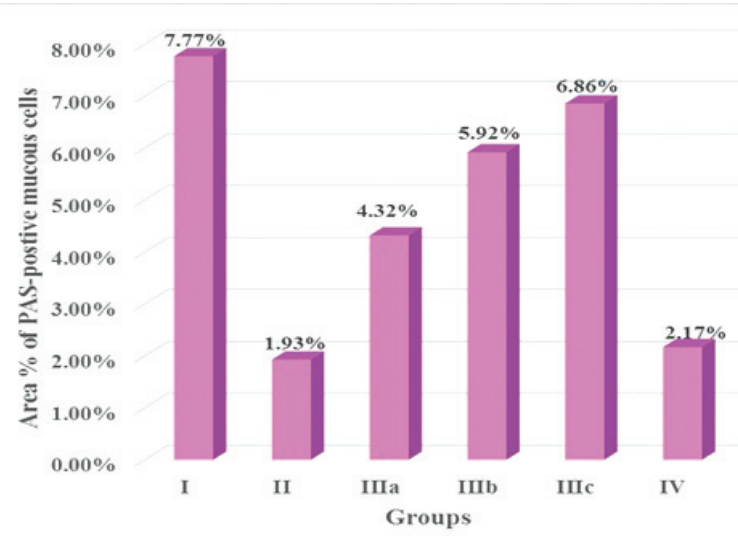

Fig. 33: A histogram for the mean area $\%$ of PAS-positive mucous cells in all experimental groups.

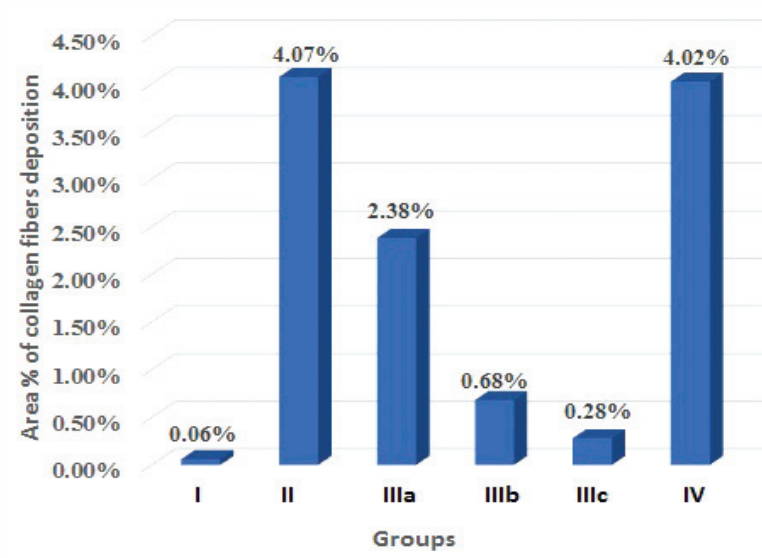

Fig. 34: A histogram for the mean area of Masson trichrome staining of collagen fiber deposition in all experimental groups.

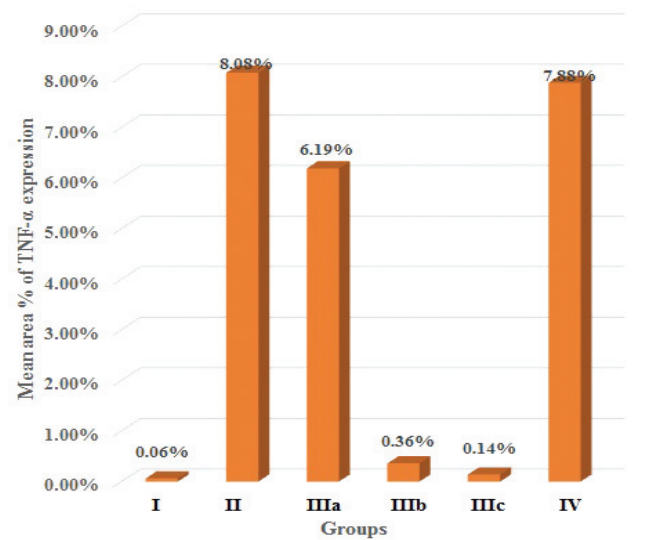

Fig. 35: A histogram for the mean area $\% \mathrm{TNF}-\alpha$ expression in all experimental groups. 


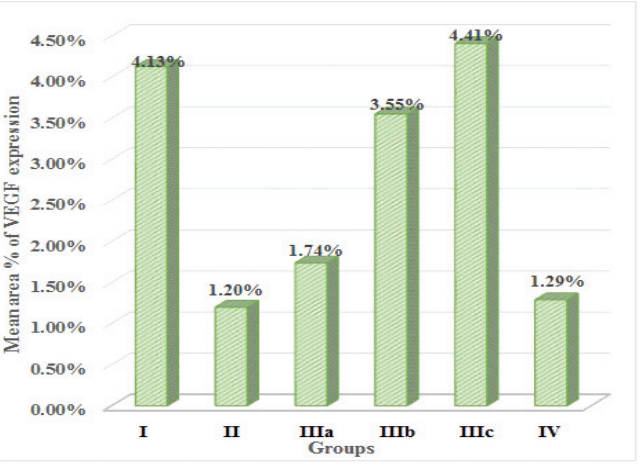

Fig. 36: A histogram for the mean area \% of VEGF expression in all experimental groups.

\section{DISCUSSION}

Gastric ulcer is the most widespread gastrointestinal tract disorders and gastric mucosa is recurrently exposed to several destructive and injurious factors ${ }^{[1]}$.

There are different models for inducing the experimental gastric ulcer such as non-steroidal anti-inflammatory drugs and many other agents. In the current study, gastric ulcer was induced by ethanol as it has a rapid infiltration rate to the gastric mucosa impairing gastric self-protective mechanism. It also has several pathological characteristic properties of the human peptic ulcer ${ }^{[25,26]}$.

The histological examination of fundic mucosa sections of group II revealed various alterations as deep erosion and marked damage of most of the cells. There were some exfoliated cells appearing in the lumen, besides, intraepithelial lymphocytes and extra-vasated RBCs. These results were in accordance with some investigators $^{[1,27-29]}$, who reported that the ethanol had direct effect on gastric mucosa and had ability to induce necrosis of the surface gastric epithelial cells and also erosion. The presence of inflammatory cells infiltration and intra epithelial lymphocytes in gastric mucosa indicates ongoing inflammation. Intra epithelial lymphocytes serves a wide range of functions in the gastric mucosa such as, elimination of injured and infected cells, preserving epithelial barrier functions thus contribute to the healing of gastric epithelium ${ }^{[30]}$. These changes were supported by a significant increase of expression TNF- $\alpha$ immunostaining, which was an indicator of gastric inflammation and also by a significant increase in collagen fibers depositions.

Ethanol-induced ulcers increased expression of different cytokines as IL-6, IL-8 and TNF- $\alpha$ and chemokine's, which are directly chemotactic to leukocytes and other cells that arekey regulators of inflammatory processes. Furthermore the defect of the gastric mucosal barriers might cause bacterial invasion. These bacteria were also chemotactic factor for mononuclear cells leading to gastritis and mucosal ulceration ${ }^{[26,31]}$. Moreover, the aforementioned cytokines had a vulnerable role in stimulation of fibroblasts and transforming them into myofibroblasts, that initiate fibrosis $^{[25,29,32]}$.

Group II of our study revealed significant decrease of PAS positive reaction in fundic mucosal cells, consistent with some researches ${ }^{[3,7,33,34]}$, whereas ethanol-induced ulcer was associated with decrease of PAS positive reaction in fundic mucosal cells as result of ethanol damaging effect on the mucus cells or excessive oxidative stress. Moreover, there was a significant decrease of expression VEGF immunostaining in gastric mucosa, similar to some previous histopathological studies ${ }^{[35,36]}$.

The mechanism of action of ethanol induced gastric ulcer mediated through multifactorial process as various cytokines release, lipid peroxidation, generation of reactive oxygen species, oxidative damage, modification in permeability and depolarization of the mitochondrial membrane before cell death ${ }^{[7,26,37]}$. Previous related studies $^{[1]}$ revealed that the strong antioxidant action of the pomegranate peel extract had adequate potential as an antiulcer mediator.

Subgroup IIIa revealed incomplete restoration of epithelium with presence of intra epithelial lymphocytes, together with a significant increase in the PAS positive reaction in fundic mucosal cells and a significant decrease in the collagen fibers deposition. Furthermore, the immunostaining results in subgroup IIIa revealed a significant decrease of the expression of TNF- $\alpha$, while expression VEGF was significantly increased as compared with group II. These results were in compatible and confirming the findings of some investigators ${ }^{[1,12,38]}$, who reported that pomegranate stimulates the production of prostaglandin E2 (PGE2), and produces mucus later. Thus, protects the digestive tract against injury, it also improves blood supply and stimulates the release of VEGF. In consonant with our results, several researches ${ }^{[8,12]}$ attributed the anti-inflammatory effect of pomegranate to the down regulation of cytokines such as TNF- $\alpha$, IL-1, and IL-6. In addition, the preventative effect of pomegranate could be related to its flavonoids and polyphenolic contents, which had intense anti-oxidative activity and inhibited of lipid peroxidation and nitric oxide production ${ }^{[8,39]}$.

MSCS are undifferentiated cells able to develop into numerous cell types. Stem cells of stomach are present in neck-isthmus regions and are surrounded by myofibroblasts that extend through the lamina propria and merge with pericytes of the blood vessels. Stem cells secrete growth factors as HGF, KGF and they are essential for regulation of epithelial proliferation and differentiation ${ }^{[40]}$. Exogenous stem cells have been studied as experimental treatment to enhance tissue repair, wherever they can offer a hopeful alternative for the treatment of injured tissue $e^{[5]}$. 
In the current work, subgroup IIIb revealed complete restoration in gastric mucosa with almost normal mucous cells, in addition to presence of inflammatory cell infiltration, increase in PAS positive reaction in fundic mucosal cells, and decrease in collagen fibers deposition. Furthermore, a significant decrease of expression TNF- $\alpha$ revealed, while a significant increase of expression VEGF was detected as compared with group II.

Alike, previous researchers ${ }^{[2,41]}$ stated that MSCs played a serious role in gastric ulcer healing in rats by migrating and homing into lesion and damaged gastric mucosa and thus hasting the repair of gastric ulcer. Others proven that MSCs had a special efficiency in curing gastric ulcer as result of increasing secretion of growth factors "e.g., EGF \& VEGF" which induced the angiogenesis and preserved the vascular permeability. Moreover MSCs reduced the liberation of inflammatory mediators and cytokines which minimized the damaging effect of inflammation ${ }^{[36,41]}$.

The effectiveness of stem cell treatments mainly depends on suitable control of the role and death of the transplanted cells. So, the policies for improving stem cell survival, proliferation and differentiation considered as the most interesting research points ${ }^{[14]}$.

Subgroup IIIc revealed a marked improvement proven via the histological and immunohistochemical findings as complete restoration in gastric mucosa with normal mucous cells increase in the PAS positive reaction in fundic mucosal cells, decrease in the collagen fibers deposition. Furthermore, a significant decrease of expression TNF- $\alpha$ immunostaining, while a significant increase of expression VEGF immunostaining were detected as compared with group II. These results were in agreement and confirming the findings of some researchers ${ }^{[42,43]}$, who proved that the combination of natural antioxidant products with MSCs had a significant beneficial effect over the MSCs therapy alone. The antioxidant levels were firmly regulated within the cell and a minor alteration in the redox state could potentiated the curative effect of MSCs injection as it secrets growth factors that significantly change cell performance, survival and characteristics. At the place of injury, cells experience oxidative and inflammatory stresses, which could lead to cellular aging and apoptosis. Thus, rising of the cellular antioxidant levels could expand the survival rate of stem cells and therefore, promotes the functional repair ${ }^{[14]}$.

Group IV of the existing study showed a picture nearly similar to gastric ulcer group. These results agreed with Saleh et al., 2013 whereas, no improvement of histopathological picture could be noticed in the untreated group $^{[4]}$.

\section{CONCLUSION}

BMSCs can heal experimentally-induced gastric injury and protect the gastric tissue in rats. Administration of pomegranate in combination with BMSCs revealed better results.

\section{CONFLICT OF INTEREST}

There are no conflicts of interest.

\section{REFERENCES}

1. Moghaddam G, Sharifzadeh M, Hassanzadeh G, Khanavi M, Dolatshahi F. Anti-ulcerative potential of Punica granatum L (Lythraceae) hydroalcohol fruit peel extract. Tropical Journal of Pharmaceutical Research 2014;13(7): 1093-1097.

2. Sabiua $\mathrm{S}$, Garubab $\mathrm{T}$, Sunmonuc $\mathrm{T}$, Ajania E, Sulymana A, Nuraina I, Balogunc A. Indomethacin-induced gastric ulceration in rats protective roles of Spondias mombin and Ficus exasperate. Toxicology Reports 2015;2: 261-267.

3. AL-Wajeeh NS, Hajerezaie M, Noor SM, Halabi MF,Al-Henhena N, Azizan AH, Kamran S, Hassandarvish P. The gastro protective effects of Cibotium barometz hair on ethanol-induced gastric ulcer in Sprague-Dawley rats. BMC Veterinary Research 2017;13(27): 1-12.

4. Saleh S, El-Ridi M, Atia F, El-Kotb S, and Gizawy E. Treatment of experimentally-induced peptic ulcer in rats by hematopoietic stem cells. Med. J. Cairo Univ. 2013;81,(2): 229-236.

5. Rashed L and Fayez S. Therapeutic potential of mesenchymal stem cells in the treatment of gastric ulcer. Adv. Environ.Biol.2015;9(18): 1-7.

6. Mabeku LB, Nana BN, Bille BE, Tchuenguem RT, Nguepi E. Anti-Helicobacter pylori and anti ulcerogenic activity of Aframomum pruinosum seeds on indomethacin-induced gastric ulcer in rats. Pharmaceutical Biology 2017;55(1): 929-936.

7. Almasaudi SM, Abbas AT, Al-Hindi RR, ElShitany NA, Abdel-dayem UA, Ali SS. Manuka honey exerts antioxidant and anti-inflammatory activities that promote healing of acetic acidinduced gastric ulcer in rats. Evidence-Based Complementary and Alternative Medicine 2017; 1-12. Article ID 5413917.

8. El-Abd SS and Ibrahim MM. Effect of sodium fluoride on the oviductal mucosa of adult albino rats and the possible protective role of pomegranate peel extract: a histological and immunohistochemical study. The Egyptian Journal of Histology 2016;39: 191-202.

9. Sharifiyan F, Movahedian-Attar A, Nili N, Asgary 
S. Study of pomegranate (Punica granatum L.) peel extract containing anthocyanins on fatty streak formation in the renal arteries in hypercholesterolemic rabbits. Adv. Biomed Res. 2016;5(8): 1-17.

10. Mahmoud SA and Solaiman AA. Histological study of adult male rat seminiferous tubules following triclosan administration and the possible protective role of pomegranate juice. The Egyptian Journal of Histology 2014;37: 233-247.

11. Aboonabi A, Rahmat A, Othman F. Effect of pomegranate on histopathology of liver and kidney on generated oxidative stress diabetic induced rats. J. Cytol. Histol.2014; 6(1): 1-5.

12. Rafraf M, Hemmati S, Jafarabadi MA, Moghaddam A and Haghighian MK. Pomegranate (Punica Granatum L.) peel hydroalcoholic extract supplementation reduces pain and improves clinical symptoms of knee osteoarthritis: a randomized double-blind placebo controlled study. Iran Red. Crescent Med. J.2017;19(1): 1-8.

13. Farzaei $\mathrm{MH}$,Abdollahi $\mathrm{M}$ and Rahimi $\mathrm{R}$. Role of dietary polyphenols in the management of peptic ulcer. World J. Gastroenterol. $2015 ; 7,(21)$ : 6499-6517.

14. Salem MY, El-Azab NE, Helal OK, Metwaly HG and Bayoumi HE. Does selenium improve the stem cell therapeutic effect on isoproterenol-induced myocardial infarction in rats? a histological and immunohistochemical study. The Egyptian Journal of Histology 2015;38: 679-691.

15. Sayed WM, Rashed LA. Therapeutic role of bone marrow-derived mesenchymal stem cells in cyclophosphamide-induced cardiotoxicity in adult male albino rat: a morphological and immunohistochemical study. The Egyptian Journal of Histology2016;39: 281-293.

16. El-Azab NE, Salem MY and Abd El-Salam S. A histological and immunohistochemical study of different therapeutic modalities for experimentally induced ulcerative colitis in rats. The Egyptian Journal of Histology 2016; 39:12-24.

17. Soleimani M, Nadri S. A protocol for isolation and culture of mesenchymal stem cells from mouse bone marrow. Nat. Protoc.2009;4: 102-106.

18. Niki H, Hosokawa S, Nagaike K, Tagawa T. A new immunofluorostaining method using red fluorescence of Per CP on formalin fixed paraffin- embedded tissues. J. Immunol. Methods 2004; 293:143-51.

19. Ibrahium MI. Efficiency of Pomegranate Peel Extract as Antimicrobial, Antioxidant and Protective Agents. World Journal of Agricultural Sciences 2010; 6 (4): 338-344.

20. Al-Qaraghuli AMS, Abdel Wahab EMN, Al-Ani IM, Faisal GG. Effects of Xians Sha Yang Wei Wan on ethanol-induced gastric ulcer in Sprague Dawley rats: a histological study. The International Medical Journal Malaysia 2013;12 (2):3-10.

21. Ahmed SK, Mohammed SA, Khalaf G, Fikry H. Role of bone marrow mesenchymal stem cells in the treatment of CCL4 induced liver fibrosis in albino rats: a histological and immunohistochemical study. Int. J. Stem Cells 2014;7(2): 87-97.

22. Attia MM, Shehab Eldien AA, Haiba DA, Mohamed SM. Effect of stem cell transplantation on amiodarone-induced hepatic changes in adult male albino rats: a histological and immunohistochemical study. The Egyptian Journal of Histology 2015;38: 295-307.

23. Das D and Banerjee RK. Effect of stress on the antioxidant enzymes and gastric ulceration. Moll Cell Biochem.1993;125(2): 115-125.

24. Bancroft JD and Layton C. The hematoxylin and $e o \neg \sin$, connective mesenchymal tissues with their stains In: Suvarna SK, Layton C and Bancroft JD, editors. Bancroft's Theory and practice of histological techniques. 7th edition. Churchill Livingstone: Philadelphia. 2013: 173-212 and 215-238

25. Arab HH, Salama SA, Omar HA, Arafa ESA, Maghrabi IA. Diosmin protects against ethanolinduced gastric injury in rats: novel anti- ulcer actions. PLoS ONE. 2015;10(3): 1-21.

26. Ibrahim BM, Salama AA, Abdallah HM, Awdan SA and Shaffie NM. Study of the protective effects of flaxseed oil on ethanol induced gastric mucosal lesions in non ovariectomized and ovariectomized rats. Int. J. Pharmacol.2016;12 (4): 329-339.

27. Soni H, Shah A, Paul A, Patel G. Anti-ulcer activity of herbo-mineral formulation (Asecure cap-sule) against experimentally induced acute and chronic gastric ulcers in rats. Int. J. Pharmacol. and Clin. Sci.2014;3: 61-67.

28. Alencar NM, Pinheiro RS, de Figueiredo IS, Luz 
PS, Freitas LB, Souza TD, Carmo LD, Marques LM, and Ramos MV. The Preventive effect on ethanol-induced gastric lesions of the medicinal plant plumeria rubra: involvement of the latex proteins in the NO/cGMP/KATP signaling pathway. Evidence-Based Complementary and Alternative Medicine. 2015; Volume, 2015: 1-10,Article ID 70678.

29. Al Asmaria A, Al Shahranib H, Al Masric N, Al Faraidid A, Elfakia I, Arshaduddina M. Vanillin abrogates ethanol induced gastric injury in rats viamodulation of gastric secretion, oxidative stress and inflammation. Toxicology Reports 2016;3: 105-113.

30. Paul WE. Fundamental Immunology, 7th edition by Lippincott Williams and wilkins, Philadelphia. 2013: 836-848.

31. Ab. Rahim N, Hassandarvish P,Golbabapour S, Ismail S, Tayyab S and Abdulla M. Gastroprotective effect of ethanolic extract of curcuma xanthorrhiza leaf against ethanol-induced gastric mucosal lesions in Sprague-Dawley rats. Bio. Med. Research International 2014; Volume, 2014:1-10, Article ID 416409.

32. Yehia NM, Abdel Salam NF, Saleh HA and Bayomi NS. Effect of $\alpha$-lipoic acid on fundic gastric mucosal damage induced by acetyl salicylic acid: a histological study. The Egyptian Journal of Histology 2014;37: 280-291.

33. El-Bermawy MI. Light and scanning electron microscopic study of 5-fluorouracil-induced mucosal injury in the gastric fundus and the possible protective role of omeprazole in adult male albino rats. The Egyptian Journal of Histology 2015;38: 415-426.

34. Soliman GM, El sherbeni E and Mostafa H. Histological and immunohistochemical study of the effect of long period exposure to gold nanoparticles on the fundic mucosa of adult male albino rat. The Egyptian Journal of Histology 2015;38: 32-40.

35. Omar SM, Sweed HS, Abulsaad KA and Sharara SM. Vascular endothelial growth factor-A and transforming growth factor- $\beta 1$ expression in postmenopausal osteoporosis: a histological and immunohistochemical study. The Egyptian Journal of Histology 2014;37: 701-709.

36. Lin ZL, Zheng GW, Zhang L, Zheng JT, Chen H. Effect of transplantation of BMMSCs on pathological change of gastric precancerous lesions of rats. Asian Pacific Journal of Tropical Medicine 2015;10: 1-4.

37. Ayoka AO, Okonji RE, Ofusori DA, Komolafe OA, Bamitale OA and Fakunle JB. Effect of Xylopia aethiopica, Fiscus mucuso and Anthocleista vogelli extracts on some biochemical parameters following ethanol-induced toxicity. British Journal of Medicine \& Medical Research 2014; 4(14): 2705-2712.

38. Sharma P, McClees SF and Afaq F. Pomegranate for prevention and treatment of cancer: An update. Molecules.2017; 22,177: 1-18.

39. Al-Olayan EM, El-Khadragy MF, Metwally DM and Abdel Moneim AE. Protective effects of pomegranate (Punica granatum) juice on testes against carbon tetrachloride intoxication in rats. BMC Complementary and Alternative Medicine 2014;2014,14(164):1-9.

40. Lanza R, Atala A. Essentials of stem cell biology, 3rd edition, El Sevier,2014:343-371.

41. Abd-Elmenm SM, Greish SM, Atwa MM, Fathelbab M. Evaluation of the role of adiposederived stem cells in the healing of Indomethacininduced gastric ulceration in rats. J. Cell Sci. Ther.2016;7(4):1-5.

42. El-Attar S, Elsayed LA and Rashed L. Role of stem cells and antioxidant on modulation of body defense mechanism in lipopolysaccharideinduced acute lung injury in rats. Med. J. Cairo Univ.2012;80(1): 559-573.

43. Saparov A, Chen CW, Beckman SA, Wang Y, Huard J. The role of antioxidation and immunomodulation in postnatal multipotent stem cell-mediated cardiac repair. Int. J. Mol. Sci.2013;14:16258-16279. 
الملخص العربى

دراسة مقارنه للتأثير العلاجي للرمان بمفرده أو مجتمعا مع الخلايا الجذعية الميزينشيميه المستمدة

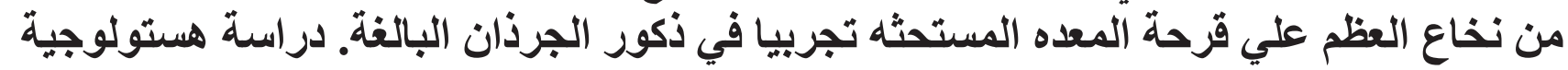
وهنتوكيميائية

\author{
نهلة العراقي العزب1 ، عائشة المنسي1 ، عبيز مصطفي المحلاوى1 ، دينا صبري2 \\ 1قسم الأنسجة و بيولوجيا الخلية ـ كلية الطب - جامعة بنها \\ 2قسم الكيمياء الحيوية الطبية والبيولوجيا الجزئيةــ كلية الطبـ جامعة القاهرة
}

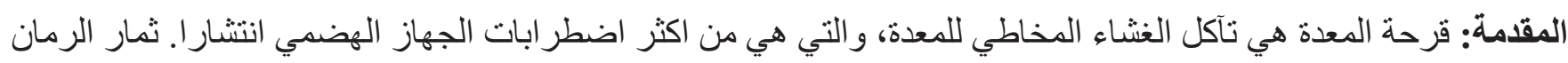

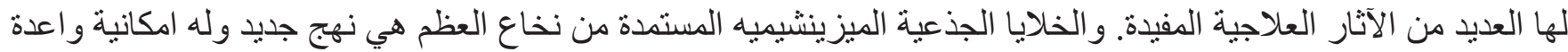

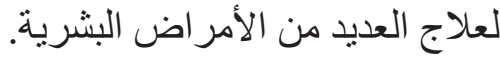

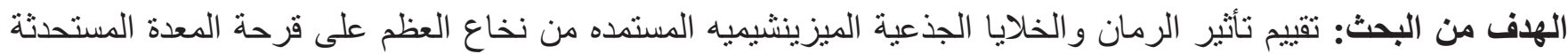
تجريبيا في ذكور الجرذان البالغين.

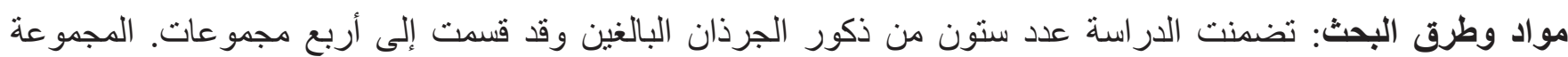

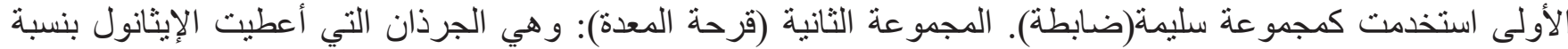

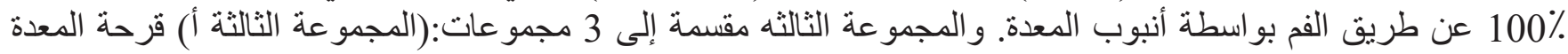

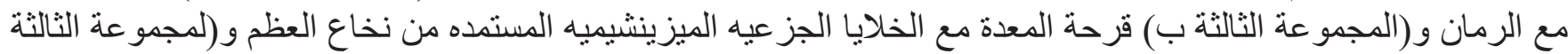

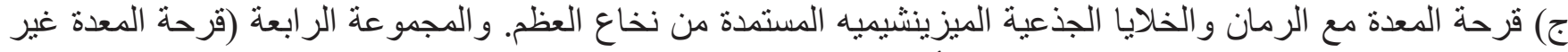

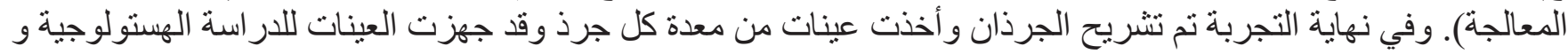
الهستو كيميائية المناعية.

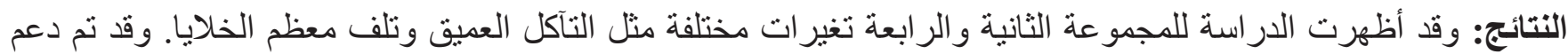

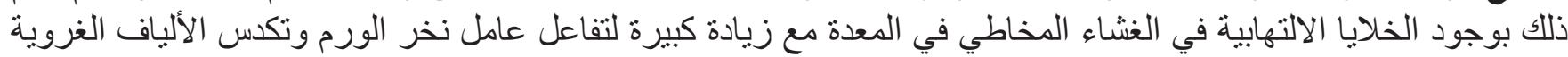

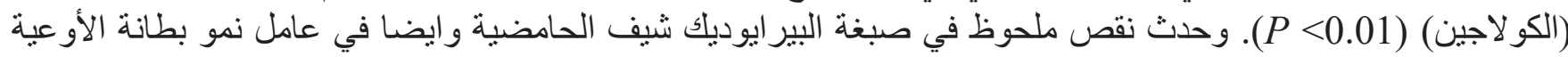

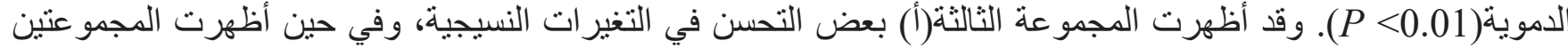

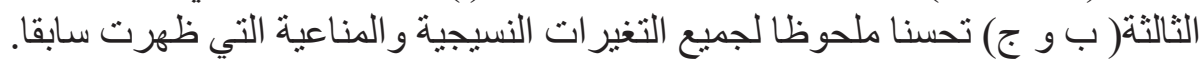

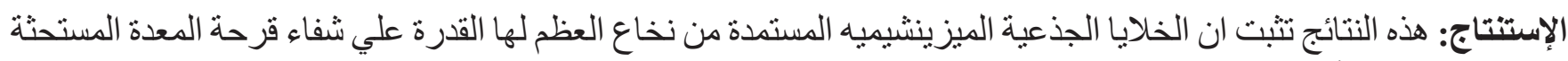

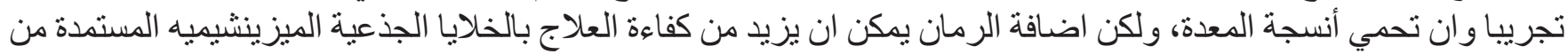
نخاع العظم عن استخدمها منفردة. 